\title{
Comparison of land passability maps created with use of different spatial data bases
}

\author{
KRZYSZTOF POKONIECZNY
}

Military University of Technology, Faculty of Civil Engineering and Geodesy, Warszaw, Poland; e-mail: krzysztof.pokonieczny@wat.edu.pl

ABSTRACT One of the key elements of military terrain analysis is the classification of terrain in terms of passability. It consists of dividing terrain into three categories: (NO GO, SLOW GO and GO TERRAIN). In this paper, the author presents the comparative analysis of passability maps created with the use of various spatial databases, including: BDOT10k, BDOO, Corine Land Cover, and OSM. They were compared to maps generated based on data included in the Military Geographic Resource (VMap Level 2 and 1). The created maps were then compared with a passability map prepared manually by the operator. In order for the maps to be comparable, an identical algorithm was used to generate them. The research consists of determining the index of passability for a square primary field of various dimensions (side length from $100 \mathrm{~m}$ to $5 \mathrm{~km}$ ). The results demonstrated that "non-military" spatial databases may be successfully used to generate military passability maps.

KEY WORDS terrain classification - cross country movement - spatial database - vegetation roughness factor - military spatial analysis

POKONIECZNY, K. (2018): Comparison of land passability maps created with use of different spatial data bases. Geografie, 123, 3, 317-352.

Received November 2017, accepted September 2018.

CC Česká geografická společnost, z. s., 2018 


\section{Introduction}

In order to ensure interoperability of operations, the armed forces of NATO (North Atlantic Treaty Organization) member states, are obliged to comply with the provisions of standardisation documents. They refer to all areas of military operations, including issues related to geospatial security. Standardisation is also applied to vector data, commonly used for editing maps and conducting spatial analyses. Pursuant to the geospatial policy of NATO (2006), homogeneous geospatial data are prepared for the strategic, operational and tactical levels. Due to the necessity to secure data for such a wide range of applications, several vector products have been developed, characterised by different levels of detail:

- Vector Map Level 0 (VMLO) - scale 1:500,000 and lower

- Vector Map Level 1 (VML1) - scale 1:250,000

- Vector Map Level 2 (VML2) - scale 1:50,000

- Vector Map Level 3 (VML3) - scale larger than 1:50,000.

In order to facilitate their use, a uniform standard for data encoding and organisation in the database has been developed, under the name DIGEST (Digital Geographic Information Exchange Standard; DIGEST 1998).

In accordance with the above mentioned, NATO Armed Forces develop and update vector maps on various levels of detail. However, there are also certain institutions and organisations that generate spatial data for the territory of e.g. Poland, to which the Armed Forces of the NATO have access and which they may freely use to complete their tasks related to geospatial security. Considering the above, the main objective of this paper is to verify the extent, to which various other, mainly "non-military" spatial databases may be used as one of the most commonly performed types of spatial analysis, i.e. military terrain classification in terms of passability. Pursuant to standardisation documents (Field manual 5-33 Terrain Analysis 1990), it consists of dividing the operational area into three classes: impassable terrain (NO GO), low-passability terrain (SLOW GO) and passable terrain (GO TERRAIN). This paper presents the methodology of automated generation of this type of maps. It consists of determining the so-called index of passability (denoted IOP). This is an estimator that reflects the degree of limiting the speed of vehicles by land cover elements. For the purposes of this study it was determined in a continuous range from 0 (impassable terrain) to 1 (perfect traction parameters). The obtained passability maps, generated basing on various databases, were referred to maps created manually in military units by reconnaissance cell officers. The analysis allowed for the verification, whether automatically generated maps may substitute maps created manually. The paper also discusses an essential aspect related to the level of detail of the generated passability maps. 
Research on the use of various data to model terrain passability was conducted by Hubáček et al. (2015). This study presented a model of passability through forested areas. It contained an analysis of the possibility to use official data and imaging obtained from the UAV (Unmanned Aerial Vehicle) to generate such maps. The algorithm of the application of the mathematical model developed by the authors to calculate the index of passability was presented in the paper by Hofmann et al. (2014). The authors performed the automation of the passability map generating process with use of the Esri software. Their research was based on the DMÚ 25 (Digitální model území) database (a Czech military topographic database of a level of detail 1:25,000). The developed terrain model was based on a primary field of the dimensions $25 \times 25 \mathrm{~m}$ and it takes into account land cover elements, relief, soil and weather conditions. Another study connected to this paper is Rybanský (2007). The author presents the results of research, concerning the assessment of the influence of land cover elements on cross-country mobility. On the other hand, issues related to data quality were discussed in the study by Talhofer, Hošková-Mayerová, Hofmann (2012). The authors present the results of research on the estimation of costs of improving the quality of DMÚ 25 database with respect to its usability for generating a military passability map. It should be mentioned, that the studies quoted above refer mainly to issues related to the use, preparation and processing of various input data for the purposes of generating military passability maps. Studies that would compare passability maps generated with use of input data from various spatial databases can hardly be found.

A method of generating passability maps similar to the one discussed herein, was provided by Rybanský et al. (2015). The authors of the paper describe an algorithm for calculating the index of passability for primary fields of the side length of 10 and $25 \mathrm{~m}$. This index is determined depending on terrain formation and land cover elements. The analysis was complemented by a description of generating the fastest route between two points. The issue of automated generation of passability maps with use of Esri software is also discussed in the paper by Pokonieczny, Wyszyński (2016). Generating military passability maps with use of artificial neural networks is presented in the study by Pokonieczny (2017b). It is based on an identical data model as the one presented herein. This model is also used in the research presented in the publication Pokonieczny, Mościcka (2018). In this paper, a comprehensive study on the impact of various shapes and sizes of primary fields on the accuracy and applicability of the developed military maps of passability was carried out.

An important project regarding the modelling of the Cross Country Movement, is the NATO Reference Mobility Model (NRMM). It was developed and validated in the 1960s and '70s by U.S. Army Tank Automotive Research, Development, and Engineering Center (TARDEC) and Engineer Research and Development Centre (ERDC). It has been revised and updated over the years to $\mathrm{v} 2.8 .2 \mathrm{~b}$. This study is used 


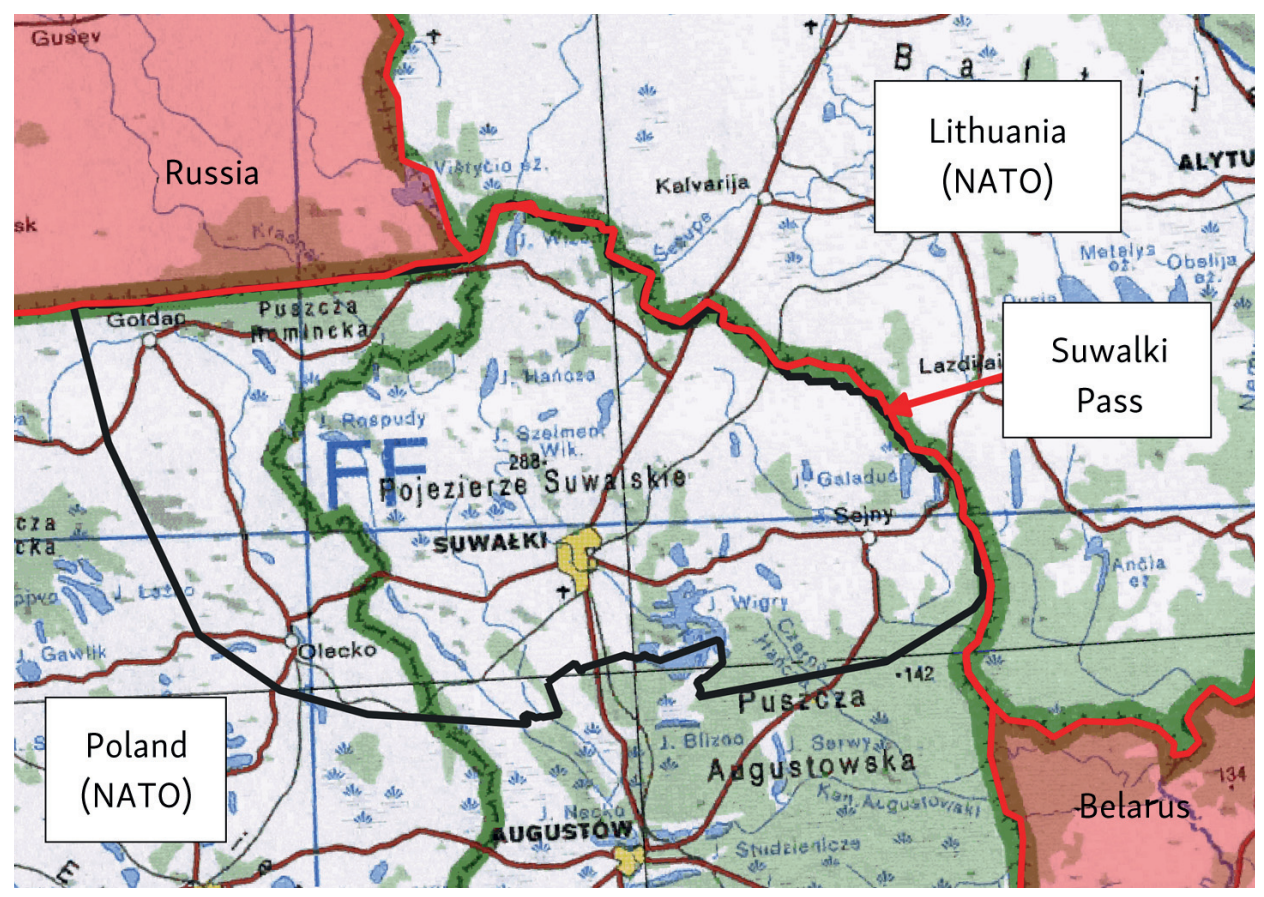

Fig. 1 - Research area

to model the mobility of various types of military vehicles and includes a comprehensive planning area for operations, including: scenario, terrain and vehicle data (McCullough et al. 2017). A detailed description of the Next-Generation NRMM can be found in the final report (Jayakumar et al. 2018). A number of studies on various aspects related to the military terrain passability are connected with this model. One of them is a work of Gonzalez, Jayakumar, Iagnemma (2016) which describe a framework for a stochastic approach for vehicle mobility prediction over large regions for integration into a NRMM. The main source of uncertainty, considered in this work, derives from uncertainty in terrain elevation, which arises from sampling (at a finer resolution) a Digital Elevation Model. Analyses related to the verification of the previous version of this model are presented in the article by Lessem, Mason, Ahlvin (1996), while the comparison of NRMM with other models in the scope of ability of military vehicles to traverse soft soils, is presented in the paper by MacLaurin (2007). The influence of soils on the trafficability were also presented in the work by Jayakumar, Mechergui, Wasfy (2017), where analyzed soil characteristics on mobility parameters such as wheel sinkage, wheel slip, vehicle speed, and tractive force and in the paper by Rybanský (2015), where author identify of main soil factors, that affect the cross-country movement modelling and the ways how we determined that factors. Mentioned papers indicate an enormous 
impact of soils on CCM (Cross Country Movement). In the method presented in this work, the development of maps focuses mainly on land cover elements located in the analysed spatial databases. However, the model described and used in this study, allows taking into account the type of soils, on which vehicles move and the current weather conditions, what is presented in the article by Pokonieczny (2017a). An example of the analysis of the impact of weather on passability conditions is the work by Shoop, Knuth, Wieder (2013), in which the authors present the results of research on the road use of vehicles moving on snow-covered areas.

\section{Method}

All the analysed passability maps were generated for the geopolitical area that is essential for both Poland and for the whole NATO, i.e. the Suwałki Pass (Elak, Śliwa 2016). This area is located in the north-eastern part of Poland and it covers approx. $3,000 \mathrm{~km}^{2}$. Apart from its enormous strategic importance, it is characterised by diversified land cover. It includes large forested areas (approx. 15\% of the surface area), vast lakes (5\%), a labyrinth shaped river network and marshes. Its northern part covers both large rugged terrain (up to 10 degrees) and large, open plains that constitute good passability terrain, as well as a large built-up area (the city Suwałki, see Fig. 1).

Military passability maps were generated for the area described above. For this purpose, the following spatial databases were used (Fig. 2):

High detailed databases:

- Vector map level 2 (VML2, military study) - it is a database equivalent to (in terms of detail) a military topographic map in the scale of 1:50,000. It covers 9 usable object categories, such as: borders, relief, physiography, transport, buildings, hydrography, vegetation, and aviation content. The structure of this database is compliant with the DIGEST standard. Due to high level of detail and costs, this product was not developed for the whole area of interest of the NATO Alliance (VMAP 1993).

- BDOT10k (BDOT, Database of Topographic Objects in the scale of 1:10,000, civilian study) - is a database equivalent to (in terms of detail) a topographic map in the scale of 1:10,000. It is the basic (reference) map included in the Polish Main Documentation Centre of Geodesy and Cartography. The objects were divided into 9 categories: water course network, communication network, utility infrastructure, buildings, structures and equipment, land use complexes, protected areas, territorial division units and other objects.

- OpenStreetMap (OSM) - is a most famous example of VGI (Volunteered Geographic Information) project, founded in the United Kingdom in 2004. 


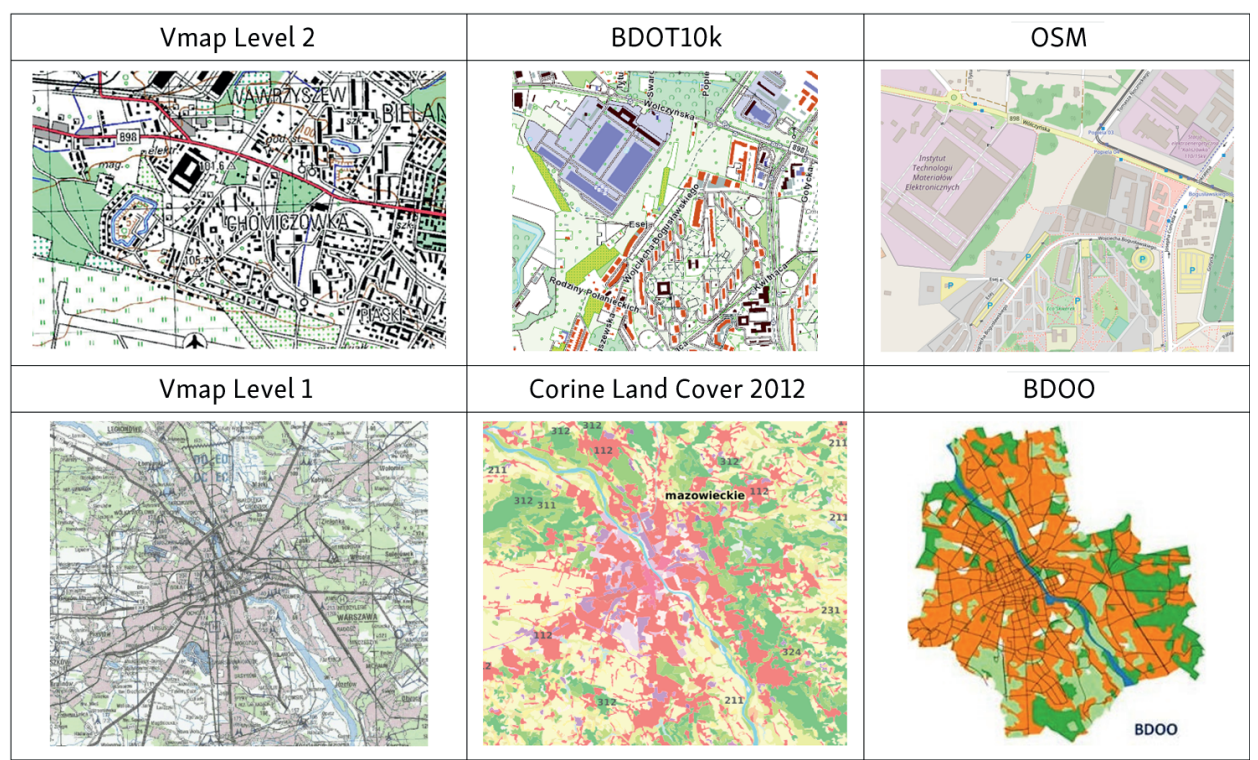

Fig. 2 - Sample visualizations of the used spatial databases

OpenStreetMap is a free, editable map of the whole world that is being built by volunteers largely from scratch and released with an open-content license. Project is supported by the not-for-profit organization - OpenStreetMap Foundation. The focus is mainly on transport infrastructure (streets, paths, railways, rivers), but OpenStreetMap also collects a multitude of points of interest, buildings, natural features and landuse information, as well as coastlines and administrative boundaries (OpenStreetMap Wiki no date).

Low detailed databases:

- Vector map level 1 (VML1, military study) - equivalent (in terms of information content) to military operational map JOG (Joint Operations Graphics) in the scale of 1:250,000. It is the first military vector product of a global reach. The scope of data and the encoding method are similar to those used in VML2. It is created by military geographic services of NATO Member States. Currently, this project has been discontinued and the data used in the analysis date back to the year 2006 (NATO 2003).

- Corine Land Cover (CLC, civilian study) - database containing information about land cover (land use) throughout the territory of Europe. It is prepared regularly (usually every 6 years) and also contains information about the changes that occurred between subsequent cycles. The database contains only surface objects grouped in the following classes: anthropogenic areas, agricultural land, wetlands and aquatic areas. The unit responsible for the coordination of CLC projects 
on the European level (since the CLC2000 project) is the European Environment Agency (EEA). The research was based on the newest version of CLC data of the year 2012 (CORINE Land Cover - Copernicus Land Monitoring Service).

- BDOO (General Geographic Database, civilian study) - is a database equivalent to (in terms of detail) a map in the scale of $1: 250,000$. It was created by means of generalisation of BDOT10k data, so the data structure and organisation in both these studies are similar.

The main assumption for the conducted research, was to refer passability to a square-shaped primary field (the IOP was calculated for the surface area of the whole square). In order to do so, grids of squares of different side lengths were generated on the analysed area (the Suwałki Pass). Used spatial databases are characterized by varying accuracy, and thus a different degree of content generalization. Taking this into account, the high-resolution spatial databases (VML2, BDOT10k, OSM) were used to develop detailed maps of passability constructed from the smallest primary fields $(100,200$ and $500 \mathrm{~m})$, while the low detailed spatial databases were used to develop less-accurate maps with the cells of 1,000 , 2,000 and 5,000 $\mathrm{m}$ sides.

For each primary field, the data listed below were obtained in an automated way, with use of a specially written software application:

- for surface object classes (e.g. forests, lakes, built-up areas) - the total surface area of each area found in the given primary field

- for linear objects (rivers, roads, railways, contours) - the total length of the linear object located within the given primary field

- for singular objects (buildings, enclosures) - the number of objects located within the given primary field.

Apart from that, a numerical terrain inclination model was generated for the analysed area. It was created with use of SRTM L1 (Shuttle Radar Topography Mission Level 1; Farr et al. 2007). Each primary field was assigned the land denivelation parameter defined as the average slope, calculated from all points of the numerical model of inclinations located in the area of the given primary field (Fig. 3).

The developed data model constituted of the basis for generating land passability maps. They were all created with use of the method based on the Vegetation Roughness Factor (denoted as IVRF and later on referred to as the "VRF method"). $I_{V R F}$ is a numerical evaluation reflecting the degree of the speed limit related to the movement of vehicles through the different types of land cover (NO-06-A015:2012, Terrain - Rules of classification - Terrain analysis on operational level 2012).

Each class of objects found in a given data model was assigned a resistance coefficient. If feature class facilitates the passability of troops, it takes the value in the 


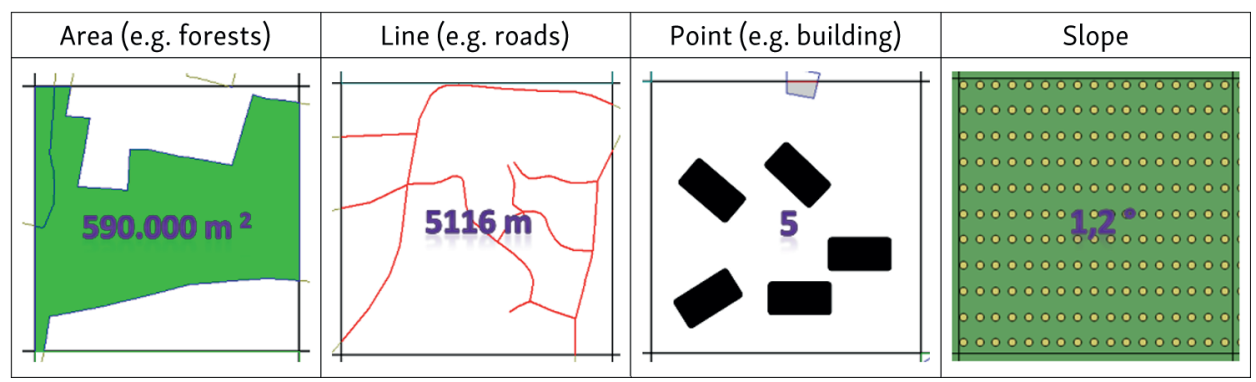

Fig. 3 - Exemplary visualisation of data in used data model

range ( $0 ; 1>$ (e.g. roads, tracks and open land), classes identified as hindering (limiting) passability were assigned the $I_{V R F}$ in the range $<-1 ; 0$ ) (waters, forests, builtup areas, etc.), while classes of objects that do not affect passability (neutral ones) were assigned a coefficient of 0 (these are mainly single objects or cartographic elements such as labels or contours). The index of passability (IOP) assigned to the whole primary field was calculated with use of the following algorithm:

- Due to the fact that information on land cover for each primary field is stored in the database in different units and that it has different numerical ranges, prior to the start of the analysis they are normalised pursuant to the formula (1).

$V^{\prime}=\frac{V-V_{\min }}{V_{\max }-V_{\min }} \cdot\left(n e w_{-} \max -n e w_{-} \min \right)+n e w_{-} \min$

Where $V$ is an input value and the $V^{\prime}$ - normalized value of input. Consequently, $\left[V_{\min }, V_{\max }\right]$ is the interval of input data and (new_min, new_max) is a new data range $(0 ; 1)$.

- Indices of passability for all primary fields were calculated with use of the following formula:

$I O P_{i}=A_{i}^{n 1} \cdot I_{V R F}^{n 1}+\cdot L_{i}^{n 2} \cdot I_{V R F}^{n 2}+N_{i}^{n 3} \cdot I_{V R F}^{n 3}+\cdots$

Where:

1. IOP is the index of passability of primary field with $i$ index.

2. For area objects, $A_{i}^{n 1}$ is a normalized area (within $i$ primary field) of $n 1$ feature class.

3. For linear objects, $L_{i}^{n 2}$ is a normalized length (within $i$ primary field) of $n 2$ feature class.

4. For singular point objects, $N_{i}^{n 3}$ is a normalized quantity (within $i$ primary field) of $n 3$ feature class.

5. $I_{V R F}$ is the Vegetation Roughness Factor of $n 1,2$ or 3 feature class.

Formula (2) takes into account all object classes that are contained in the analysed databases. 


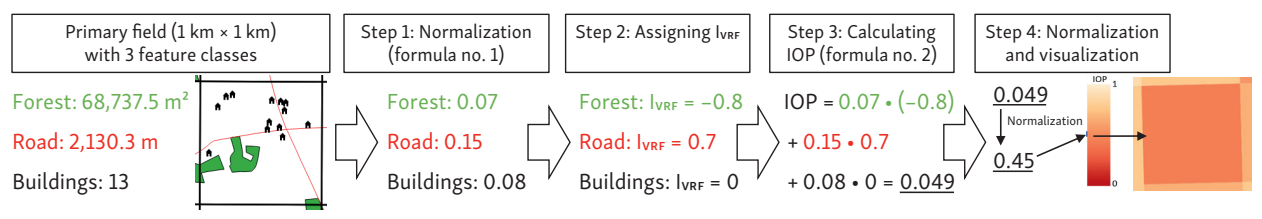

Fig. 4 - The algorithm for determining the IOP (data, used feature classes and numerical values are presented as an example)

- The obtained indices of passability are then again normalised to a constant range from 0 to 1 , pursuant to the formula (1).

A detailed description of the method presented above is provided in the work by Pokonieczny (2017a). An example of determining the Index of Passability has been presented on Figure 4.

In order to apply the methodology described above, it was necessary to assign a terrain resistance coefficient to each class of objects contained in the analysed databases. For this purpose, an analysis of the schemas of these spatial databases were conducted, with the aim to assign the same coefficient to the corresponding layers. The objective of this action was to unify the passability map generating parameters. In cases when no corresponding layers were found, the coefficient was assigned individually to a specific class of objects (Table 1 ).

As a result of the application of the above algorithm, 18 passability maps were created (maps were generated for six sizes of primary fields for each of the three spatial databases used). In order to analyse the correlations between the generated maps, Pearson Correlation Coefficient Matrices were determined for the all calculated indices of passability. Moreover, for each generated map, it has calculated global Moran's I statistics. This index measures spatial autocorrelation, based on feature locations and attribute values. It evaluates whether the spatial structures of generated IOP's creates clusters are dispersed, or random. Moran >s I value near +1.0 indicates clustering, while a value near -1.0 indicates dispersion

Table 1 - Sample corresponding resistance coefficients ( $\left.\mathrm{IVFF}_{\mathrm{VF}}\right)$

\begin{tabular}{|c|c|c|c|c|c|c|c|}
\hline $\begin{array}{l}\text { Feature } \\
\text { class }\end{array}$ & VML2 & VML1 & Corine & $\mathrm{BDOO}$ & OSM & BDOT & $I_{\text {VRF }}$ \\
\hline Forest & foresta_aft & $\begin{array}{l}\text { vegetation_ } \\
\text { trees }\end{array}$ & $\begin{array}{l}\text { n313_mixed_ } \\
\text { forests }\end{array}$ & ptlz_a & $\begin{array}{l}\text { n7201_- } \\
\text { forest_a }\end{array}$ & ptlz_a & -0.8 \\
\hline Lake & lakea_aft & $\begin{array}{l}\text { hydrogrf_- } \\
\text { reservoir }\end{array}$ & $\begin{array}{l}\text { n512_water_ } \\
\text { reservoirs }\end{array}$ & ptwp_a & $\begin{array}{l}\text { n821x_ } \\
\text { waters_a }\end{array}$ & ptwp_a & $-1,0$ \\
\hline Road & roadl_lft & $\begin{array}{l}\text { transprt_ } \\
\text { roadl }\end{array}$ & - & skdr_l & $\begin{array}{l}\text { n511x_main_ } \\
\text { roads_l }\end{array}$ & skdr_l & 0.7 \\
\hline
\end{tabular}




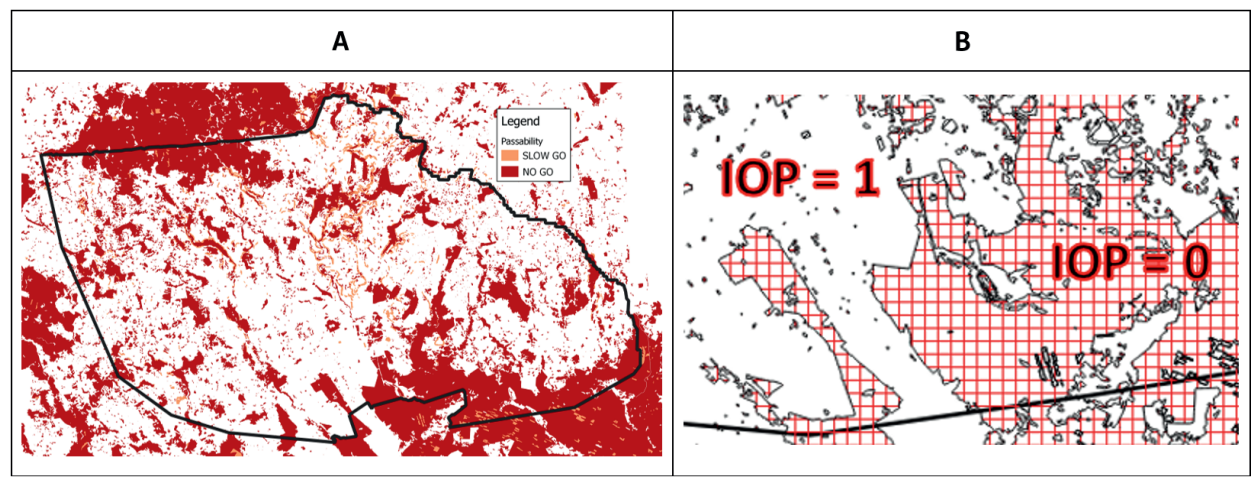

Fig. 5 - Visualizations of manually generated passability map: A -whole analysed area, B - fragment

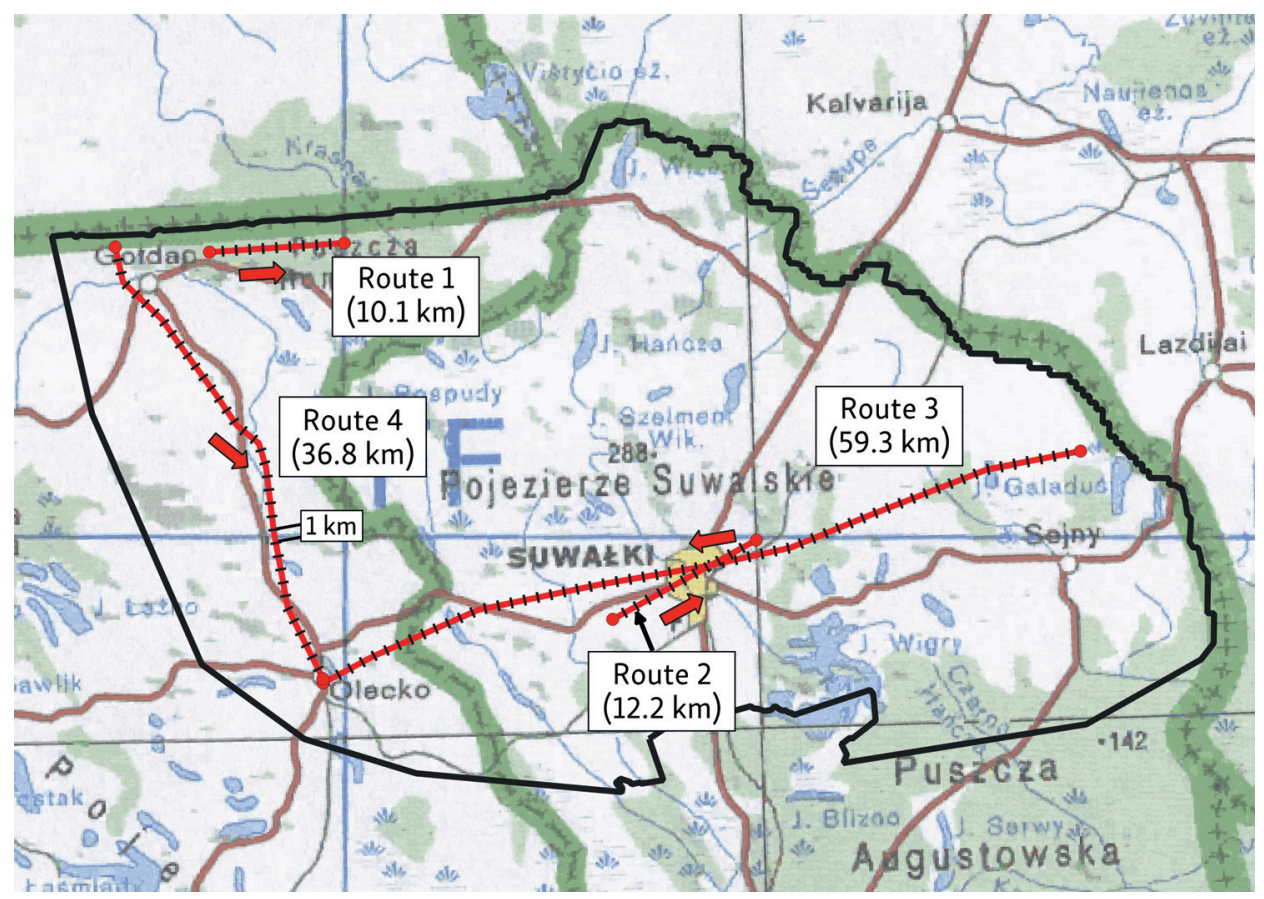

Fig. 6 - Routes along which generated maps of passability have been tested

(Goodchild 1986). The distribution of passability coefficients is presented by means of basic statistics (arithmetic average, standard deviation, kurtosis, skewness and coefficient of variation) and visualized using histograms. Moreover, maps presenting a spatial distribution of differences between the obtained passability coefficients were elaborated, as well as the tables indicating the percentage of IOPs differing from each other by an absolute value of 0.2 and 0.4 . The purpose of this 
analysis was to show how the maps generated on the basis of various input data are actually different. Additionally, maps generated automatically were referred to the map created "manually". It was prepared by means of marking impassable and low-passability terrain areas in the same way as it is done in military units (Figure 5A), based on NATO standardization agreement. It was assumed that the index of passability for NO GO areas equals 0, for SLOW GO areas equals 0.5, while unmarked areas, i.e. passable terrain, was assigned an IOP of 1 (Fig. 5B). All calculations were performed separately for each size of the primary field. The Pearson Correlation Coefficient (PCC) between all generated maps and the map created manually was also determined.

Due to the fact, that the generated maps of passability are to be used to plan the movement of troops, the change in the value of Index of Passability was compared along the sample routes (Fig. 6). Routes 1 and 2 will be used for map tests generated for primary fields with sides 100,200 and $500 \mathrm{~m}$, while routes 3 and 4 - for less accurate maps created from squares with sides 1,000, 2,000 and 5,000 m.

\section{Results}

The analysis of the schemas of the used spatial databases, allowed to assign each class of objects a resistance coefficient $\left(I_{v r f}\right)$. Depending on the characteristics of the given class of objects, it was qualified to the class that facilitates or it hinders or does not affect passability. The summary of this analysis is presented in Figure 7.

The resulting passability maps, generated with use of six topographic databases and the methodology presented in the previous section, along with the Pearson Correlation Coefficient Matrices, all calculated statistics and histograms are presented in Tables 2-7. The analyses were conducted separately for each primary

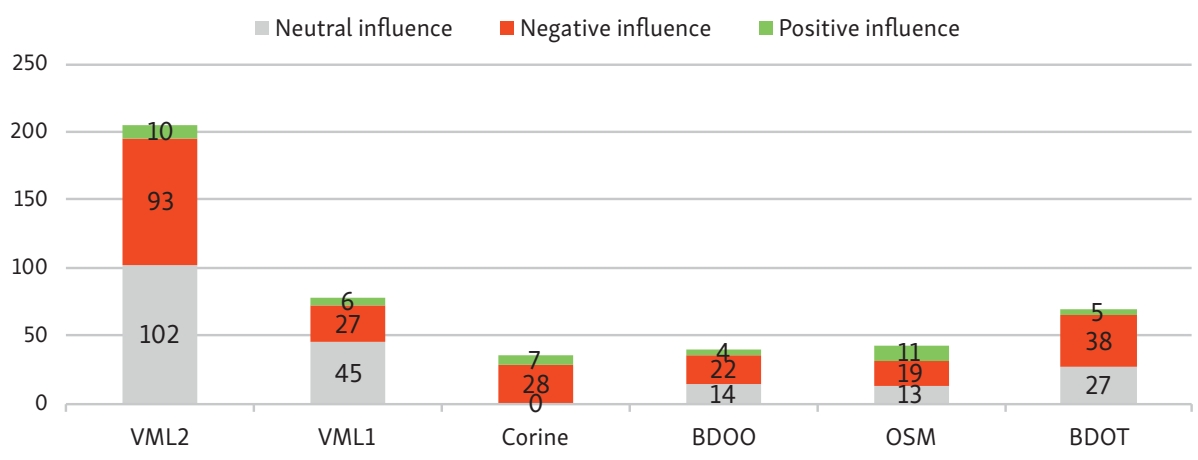

Fig. 7 - Number of object classes that have a positive, negative or neutral influence on passability, depending on the spatial database used 
field size. The tables also present the correlations between the generated maps and the manually created map.

Tables 8-13 contain maps showing the differences between IOP's generated, using a variety of spatial databases. This analysis also includes the manually created map, but due to its high detail, it was compiled only with the maps of passability, generated using detailed spatial databases (OSM, BDOT and VML2). Below the map, there are tables showing the percentage of IOP's differing from each other by a value in the range from 0 to 0.2 and from 0.2 to 0.4 (values of absolute differences were included in the calculations).

Changes in the value of the passability coefficient along the routes shown in Figure 6 are presented in Figures 8-11. The characteristic elements of land cover located in specific places of the analysed routes have been marked on them. The summary of this analysis is Table 14, which includes the sum of IOP's, calculated along all routes, for all analysed spatial databases.

Table 2 - Visualisations of passability maps, histograms and calculated statistics for the $100 \mathrm{~m}$ by $100 \mathrm{~m}$ primary field

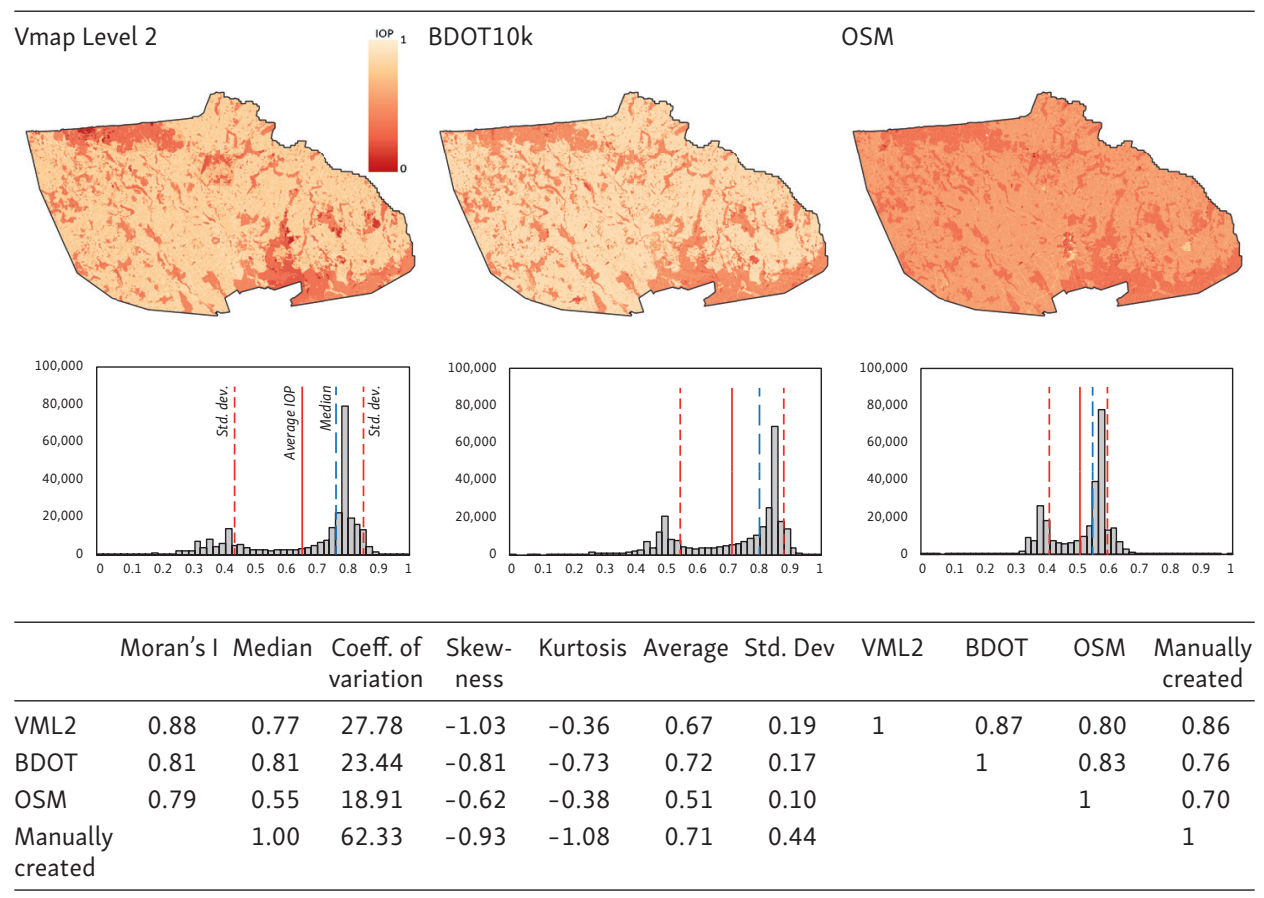


Table 3 - Visualisations of passability maps, histograms and calculated statistics for the $200 \mathrm{~m}$ by $200 \mathrm{~m}$ primary field

\begin{tabular}{l} 
Vmap Level 2 \\
\hline
\end{tabular}


Table 4 - Visualisations of passability maps, histograms and calculated statistics for the $500 \mathrm{~m}$ by $500 \mathrm{~m}$ primary field

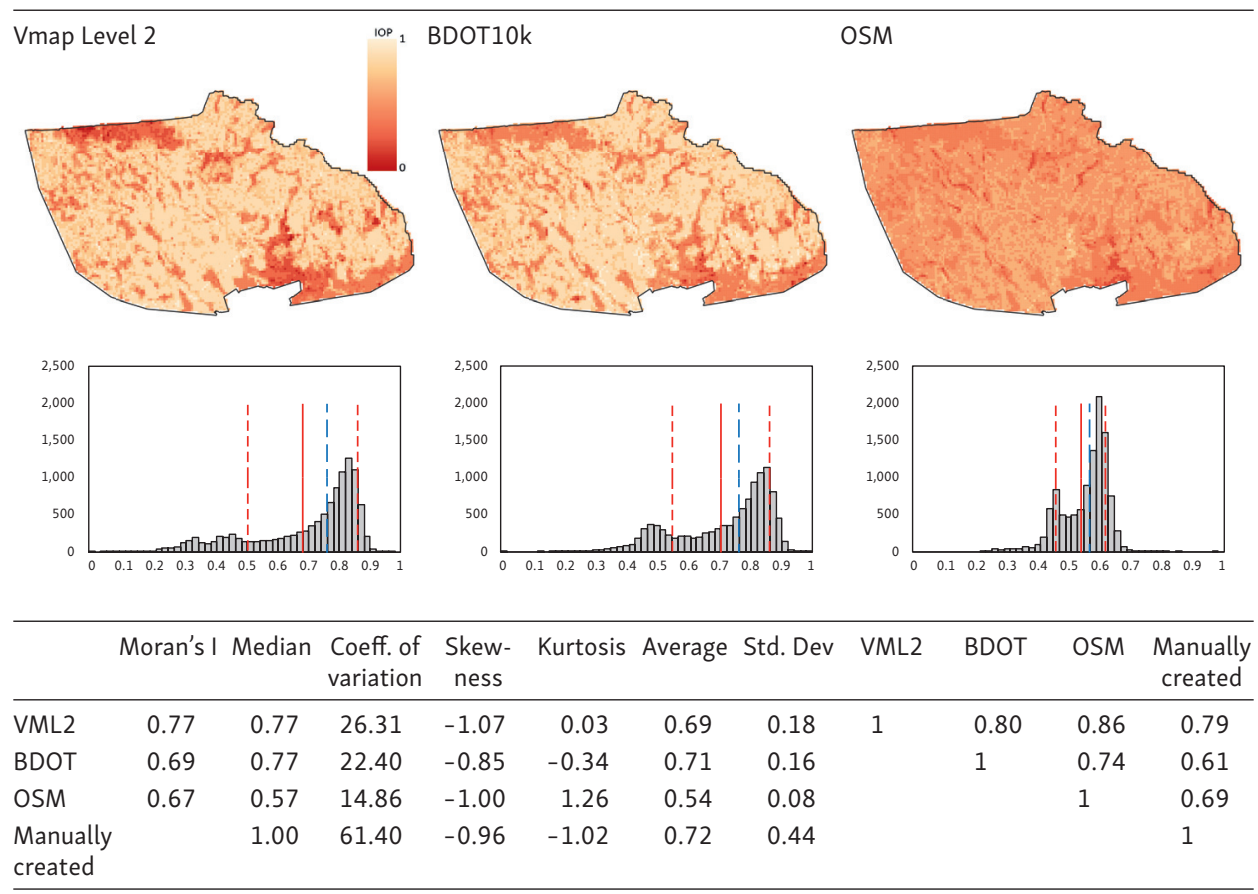


Table 5 - Visualisations of passability maps, histograms and calculated statistics for the $1,000 \mathrm{~m}$ by 1,000 m primary field

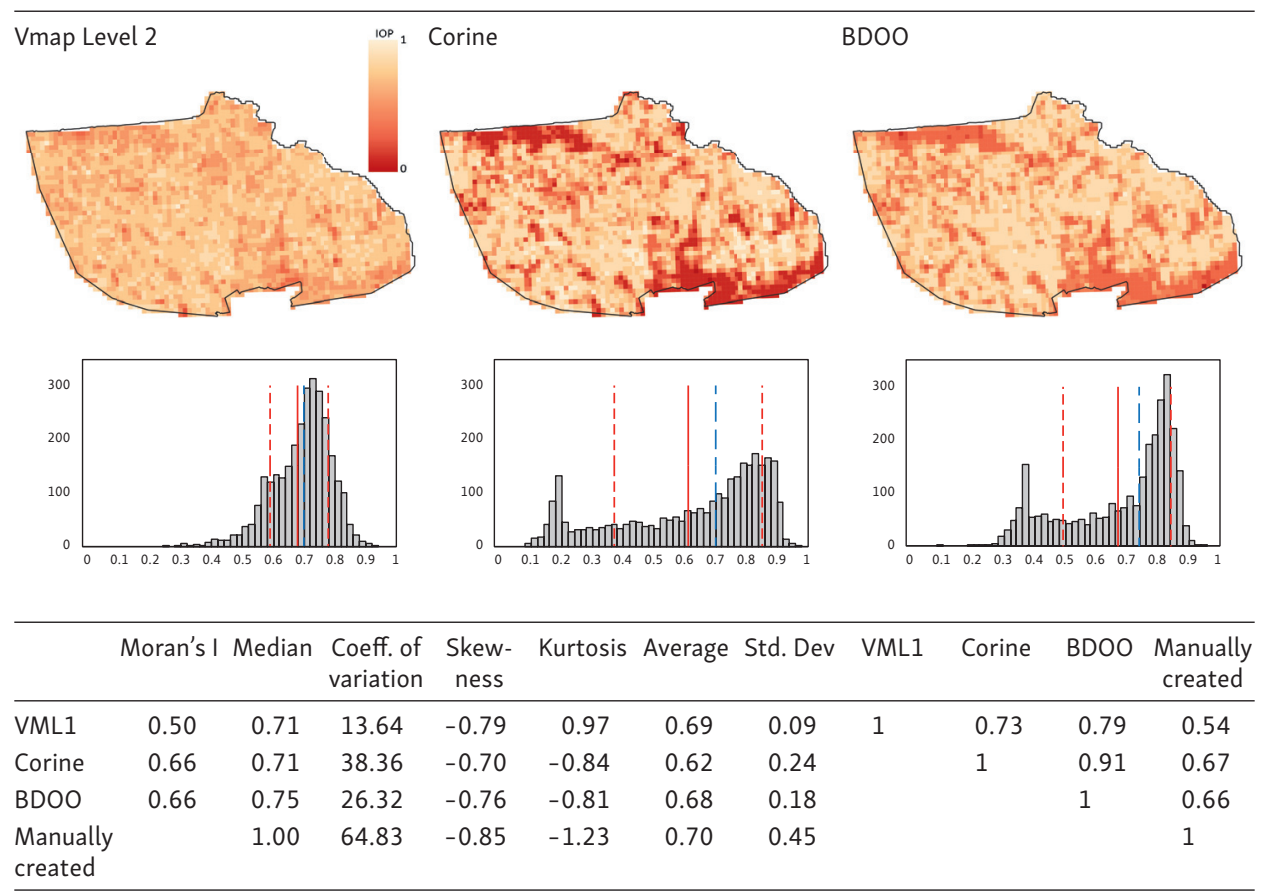


Table 6 - Visualisations of passability maps, histograms and calculated statistics for the 2,000 m by 2,000 m primary field

Vmap Level 1
DML1


Table 7 - Visualisations of passability maps, histograms and calculated statistics for the 5,000 $\mathrm{m}$ by $5,000 \mathrm{~m}$ primary field

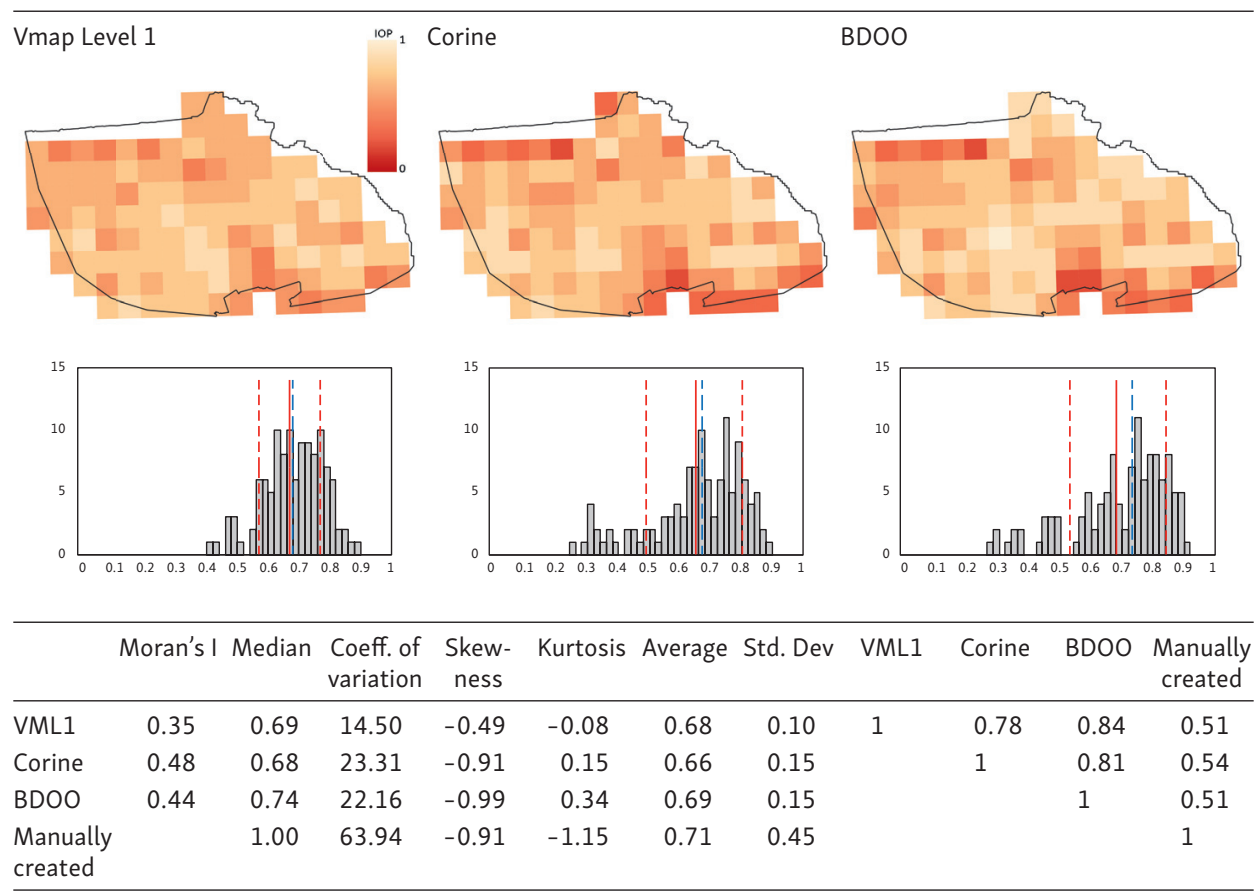


Table 8 - Visualisations of differences between IOP's and the absolute values of differences (in percentages) for the $100 \mathrm{~m}$ by $100 \mathrm{~m}$ primary field

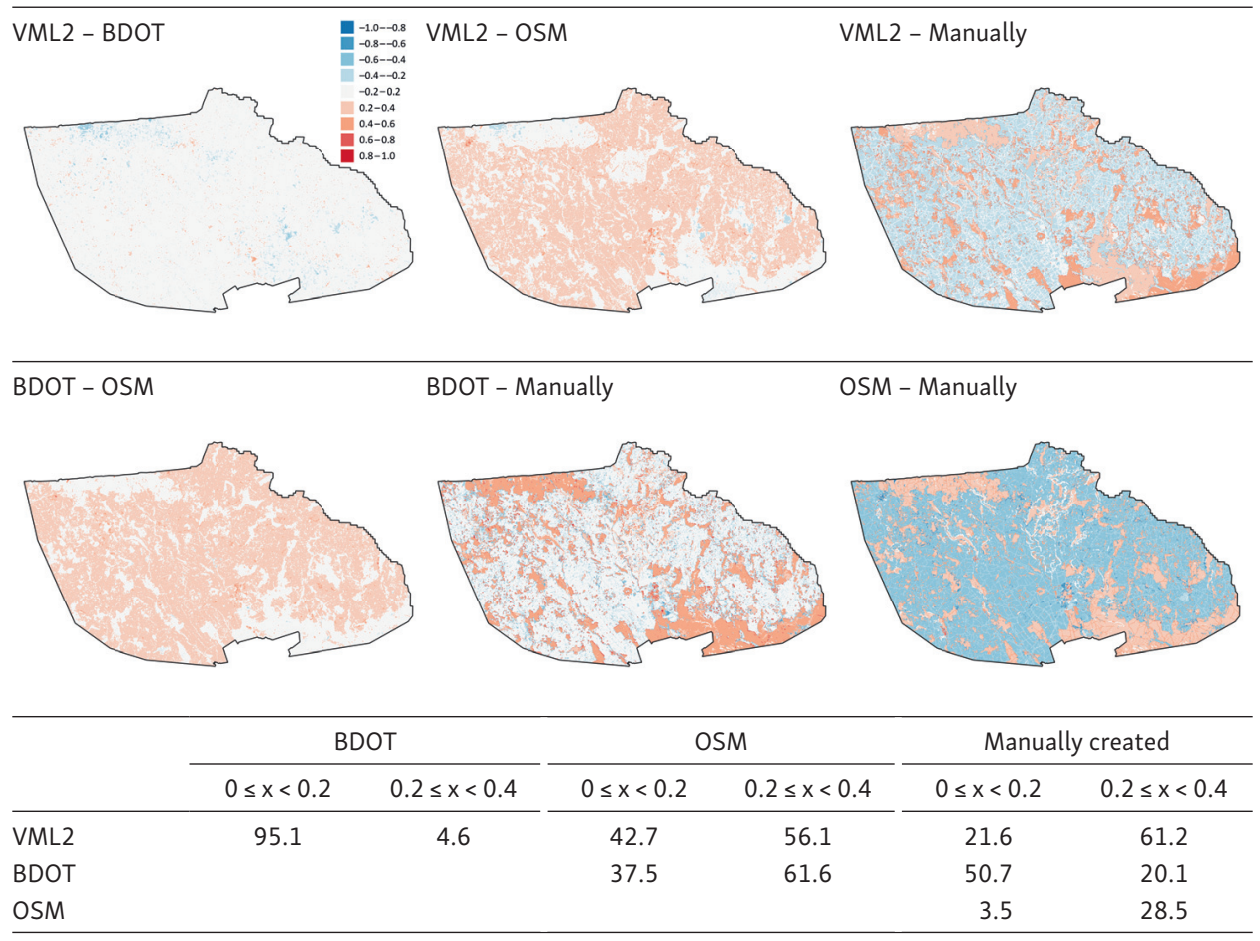


Table 9 - Visualisations of differences between IOP's and the absolute values of differences (in percentages) for the $200 \mathrm{~m}$ by $200 \mathrm{~m}$ primary field

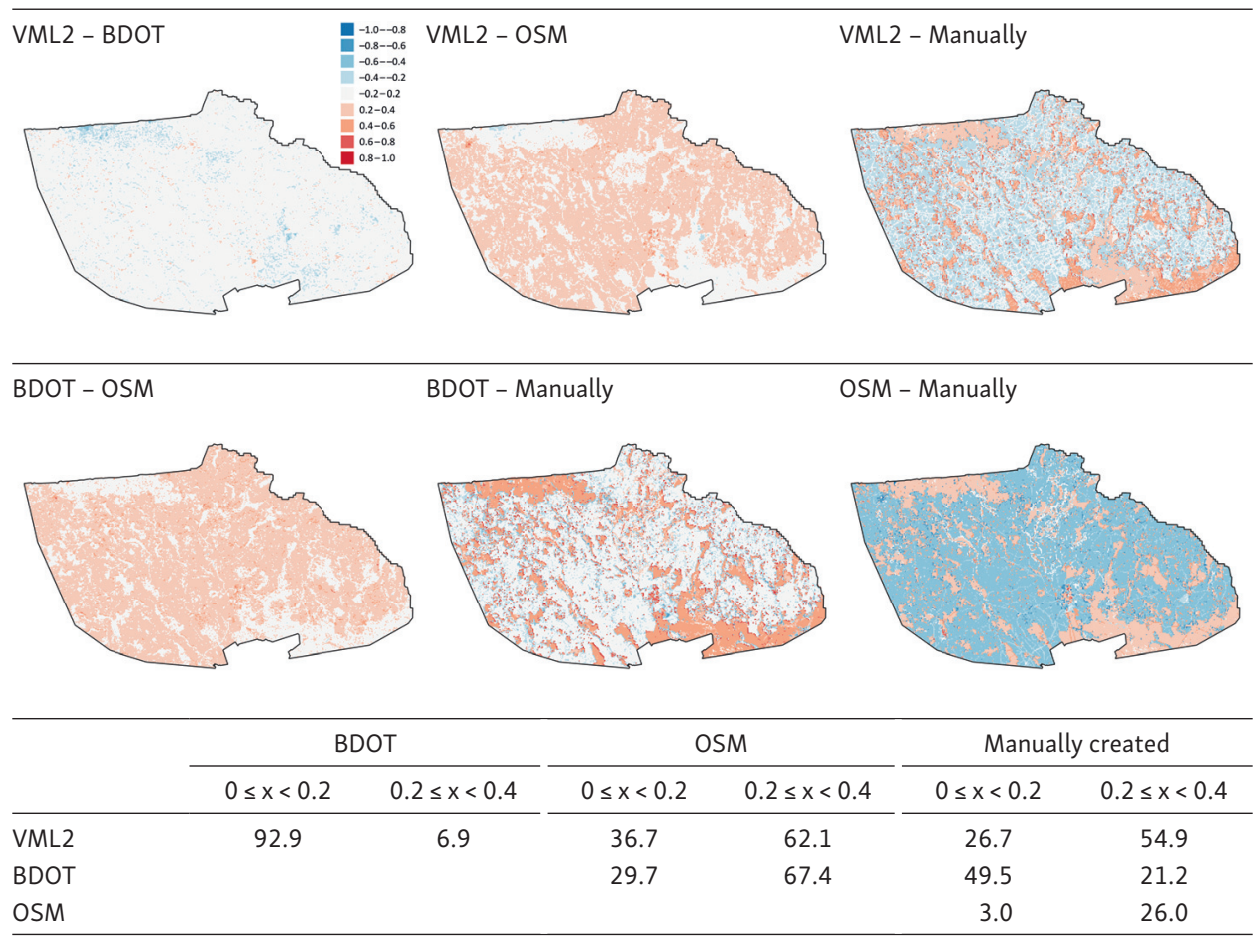


Table 10 - Visualisations of differences between IOP's and the absolute values of differences (in percentages) for the $500 \mathrm{~m}$ by $500 \mathrm{~m}$ primary field

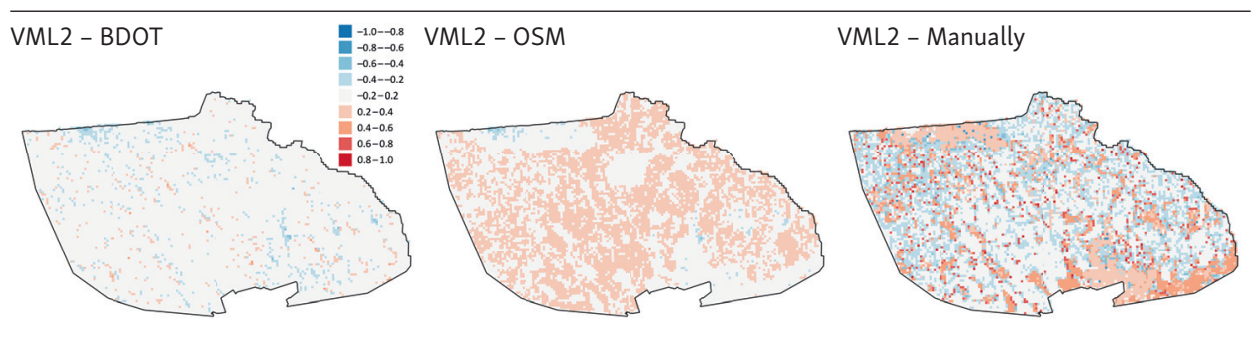

$$
\text { BDOT - OSM }
$$

$$
\text { BDOT - Manually }
$$

$$
\text { OSM - Manually }
$$

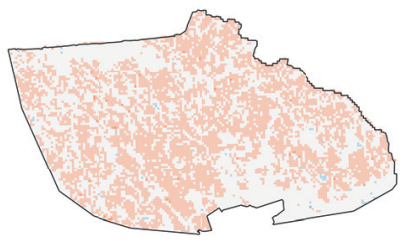

\begin{tabular}{|c|c|c|c|c|c|c|}
\hline & \multicolumn{2}{|c|}{ BDOT } & \multicolumn{2}{|c|}{ OSM } & \multicolumn{2}{|c|}{ Manually created } \\
\hline & $0 \leq x<0.2$ & $0.2 \leq x<0.4$ & $0 \leq x<0.2$ & $0.2 \leq x<0.4$ & $0 \leq x<0.2$ & $0.2 \leq x<0.4$ \\
\hline VML2 & 91.8 & 7.9 & 53.4 & 46.6 & 40.4 & 39.8 \\
\hline BDOT & & & 50.6 & 49.1 & 39.9 & 29.6 \\
\hline OSM & & & & & 3.8 & 27.6 \\
\hline
\end{tabular}
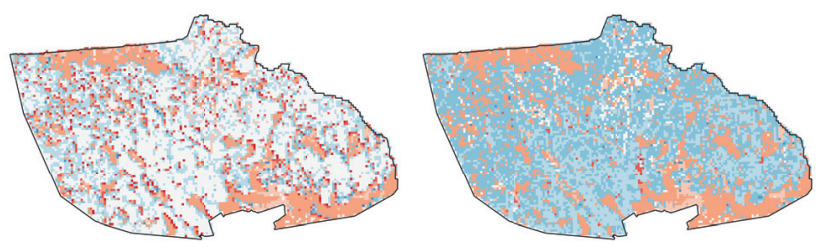
Table 11 - Visualisations of differences between IOP's and the absolute values of differences (in percentages) for the $1,000 \mathrm{~m}$ by $1,000 \mathrm{~m}$ primary field

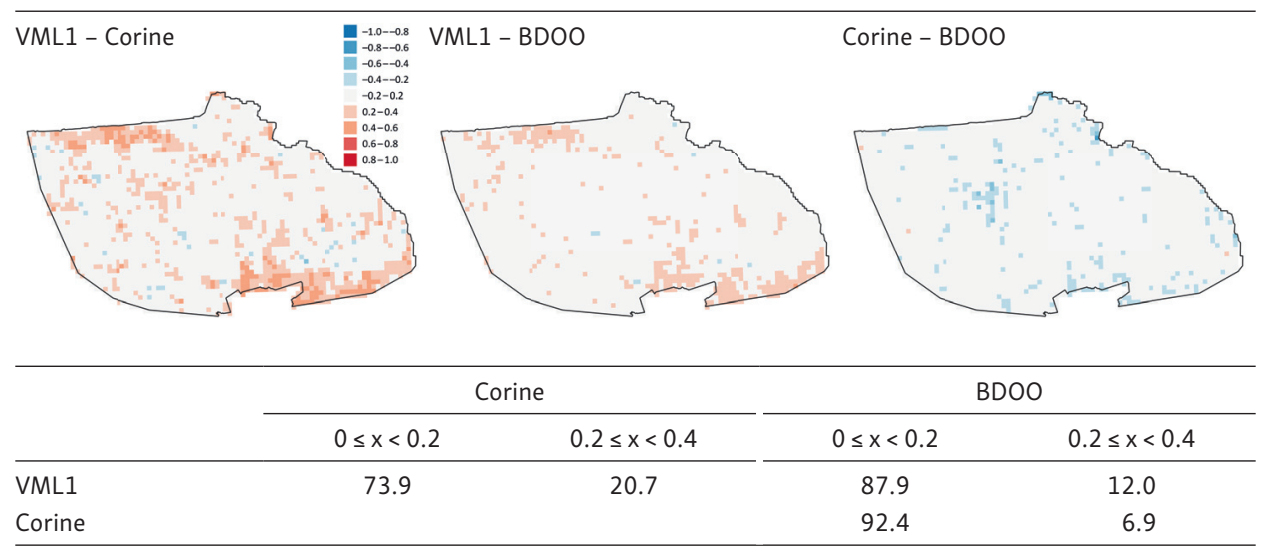


Table 12 - Visualisations of differences between IOP's and the absolute values of differences (in percentages) for the $2,000 \mathrm{~m}$ by $2,000 \mathrm{~m}$ primary field

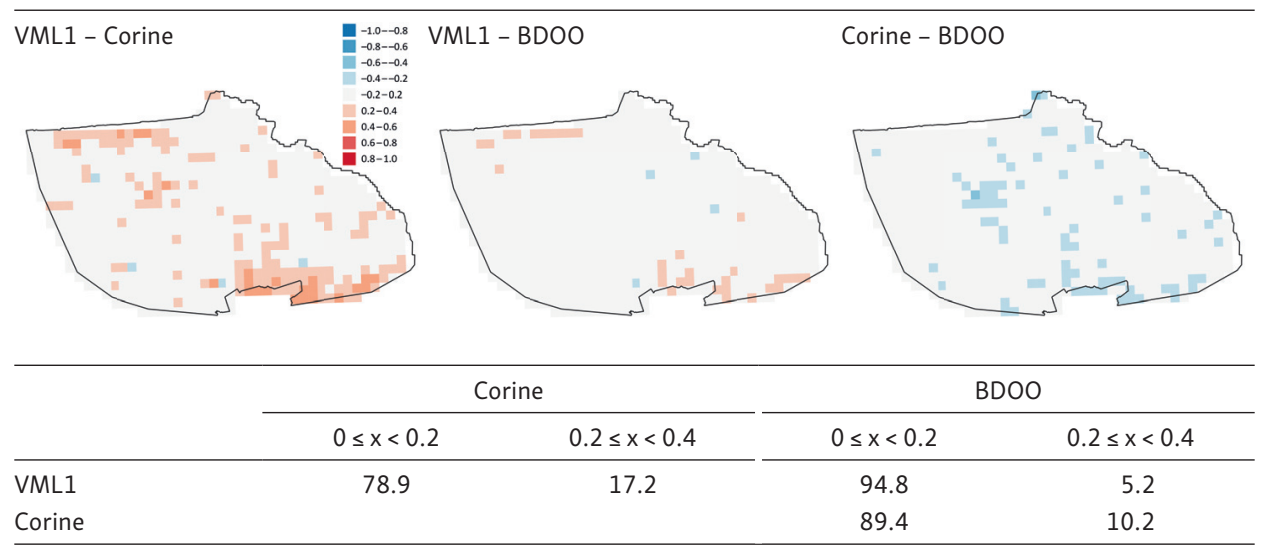


Table 13 - Visualisations of differences between IOP's and the absolute values of differences (in percentages) for the $5,000 \mathrm{~m}$ by $5,000 \mathrm{~m}$ primary field

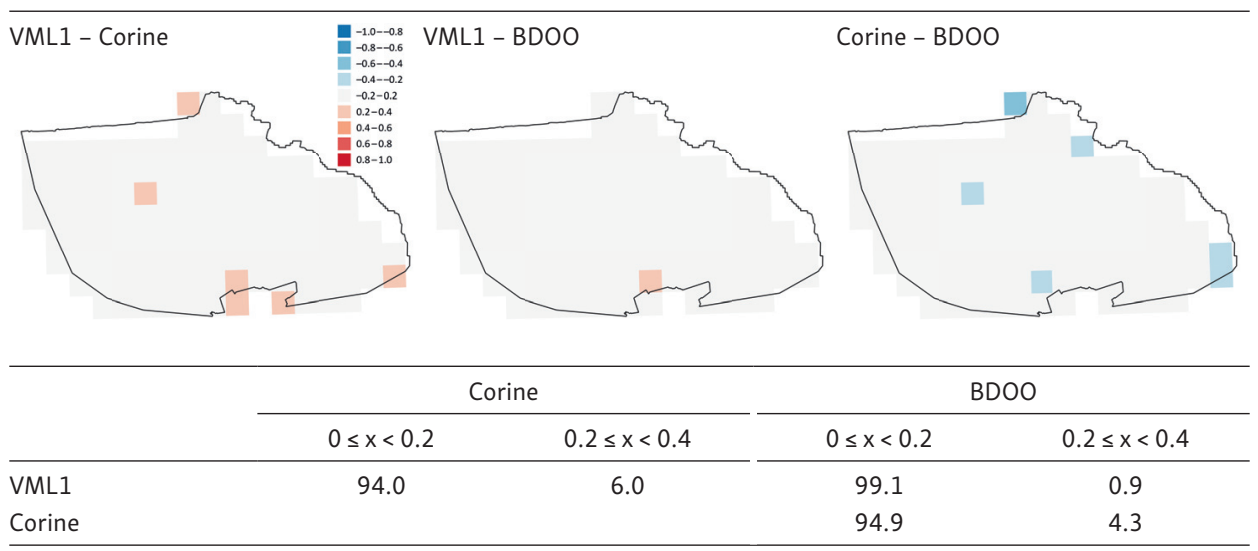

Table 14 - Sum of the IOP's along the analysed routes

\begin{tabular}{|c|c|c|c|c|c|c|c|}
\hline & VML2 & BDOT & OSM & & VML1 & Corine & $\mathrm{BDOO}$ \\
\hline Route $\mathrm{nr} 1,100 \times 100 \mathrm{~m}$ & 32.0 & 53.3 & 41.0 & Route $\mathrm{nr} 3,1000 \times 1000 \mathrm{~m}$ & 34.6 & 32.9 & 33.9 \\
\hline Route $\mathrm{nr} 1,200 \times 200 \mathrm{~m}$ & 16.1 & 27.5 & 18.7 & Route $\mathrm{nr} 3,2000 \times 2000 \mathrm{~m}$ & 17.1 & 16.1 & 17.0 \\
\hline Route $\mathrm{nr} 1,500 \times 500 \mathrm{~m}$ & 6.4 & 10.4 & 9.8 & Route $\mathrm{nr} 3,5000 \times 5000 \mathrm{~m}$ & 6.4 & 6.4 & 6.3 \\
\hline Route $\mathrm{nr} 2,100 \times 100 \mathrm{~m}$ & 121.4 & 122.8 & 81.5 & Route $\mathrm{nr} 4,1000 \times 1000 \mathrm{~m}$ & 51.7 & 49.3 & 50.8 \\
\hline Route $\mathrm{nr} 2,200 \times 200 \mathrm{~m}$ & 60.7 & 63.7 & 39.9 & Route $\mathrm{nr} 4,2000 \times 2000 \mathrm{~m}$ & 26.8 & 25.5 & 27.0 \\
\hline Route $\mathrm{nr} 2,500 \times 500 \mathrm{~m}$ & 26.6 & 25.9 & 20.6 & Route $\mathrm{nr} 4,5000 \times 5000 \mathrm{~m}$ & 10.9 & 11.0 & 11.1 \\
\hline
\end{tabular}




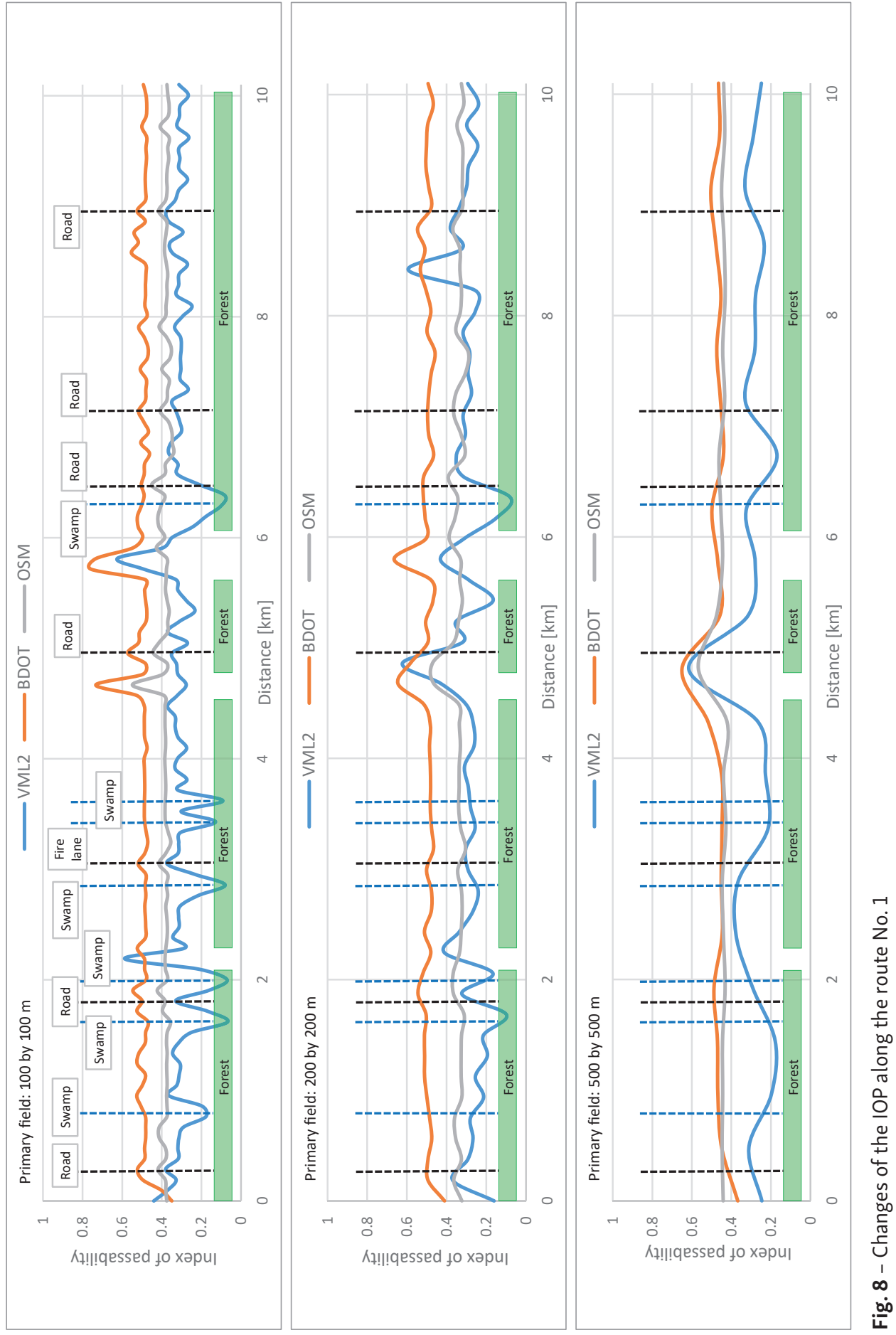




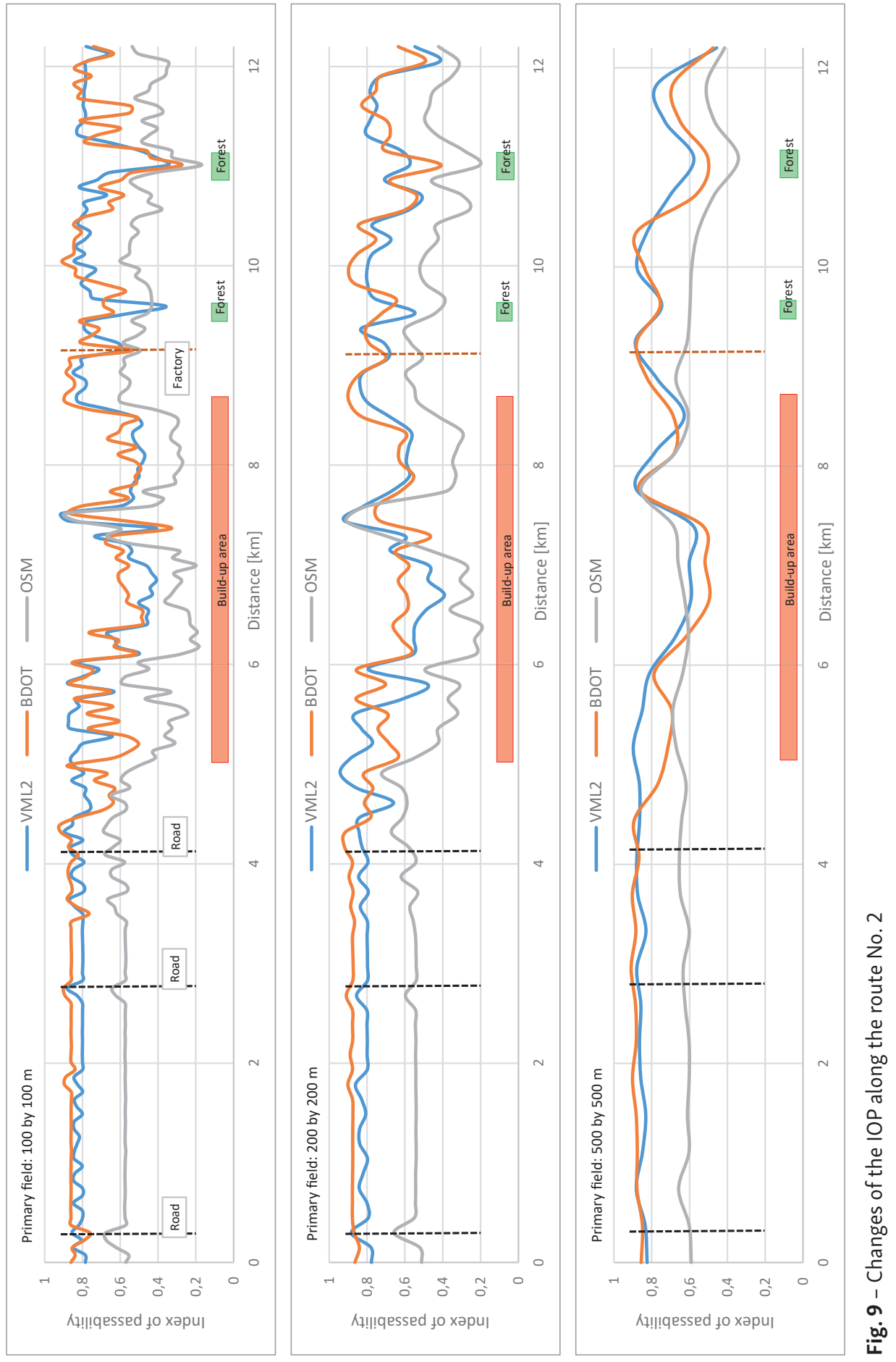




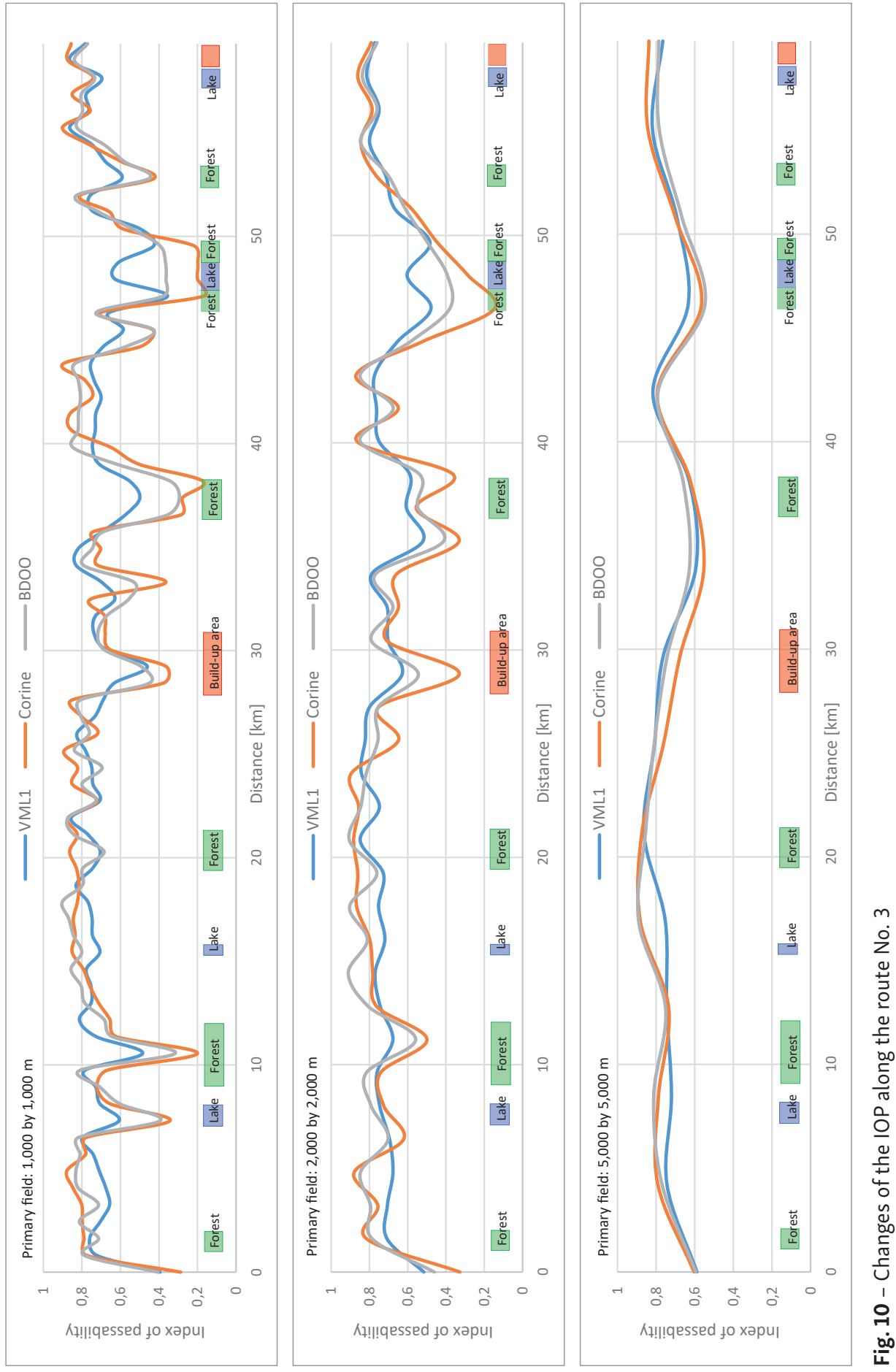




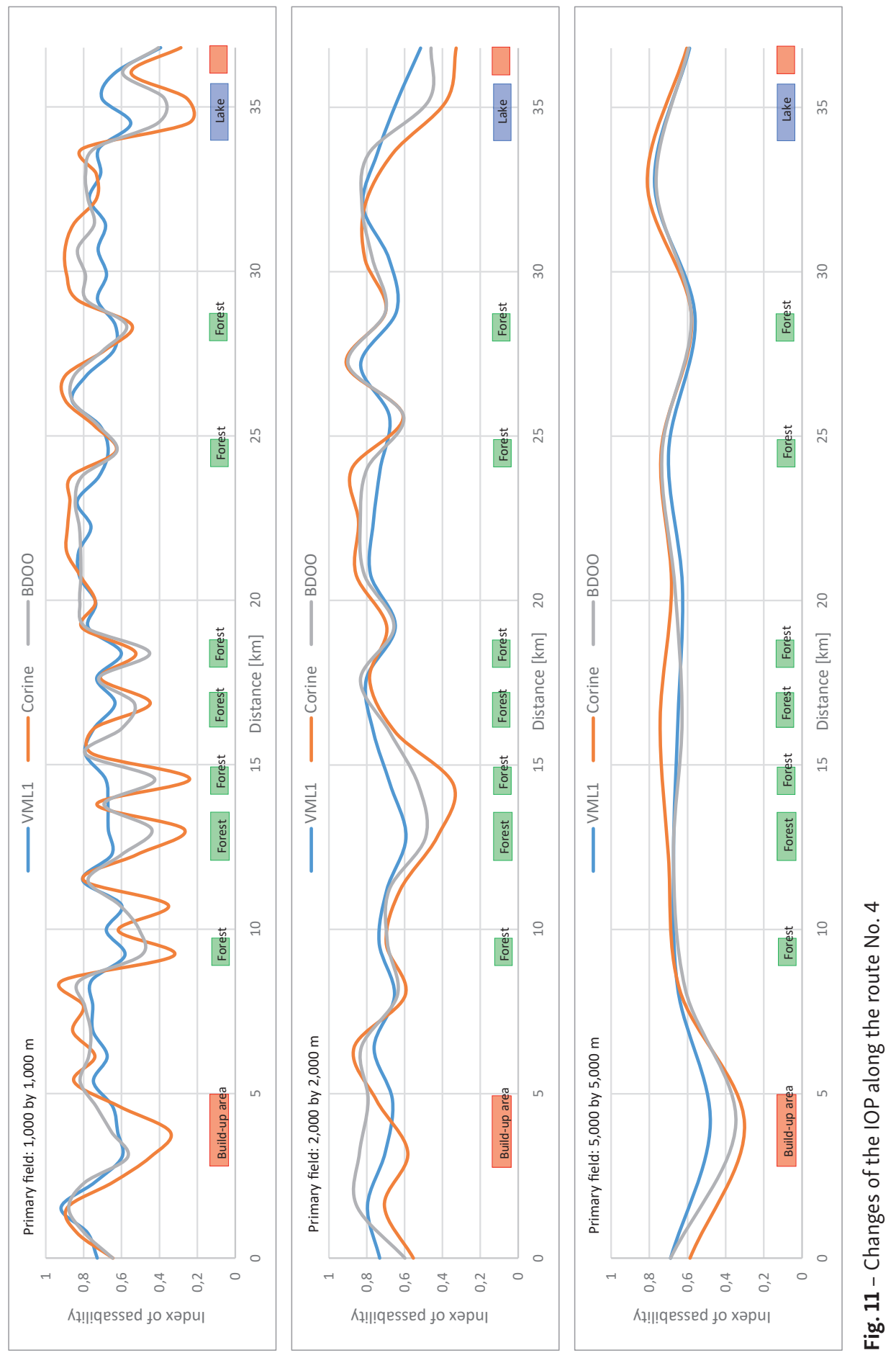




\section{Discussion}

The analysis of feature classes included in the applied spatial databases (Fig. 7) demonstrate clearly that about half of the classes in all databases were qualified as not affecting passability $\left(I_{V R F}=0\right)$. An exception is the Corine Land Cover database, in which all object classes have a non-zero (positive or negative) influence on passability. This results from the specificity of these data, which cover only distinct land cover characteristics (in form of surface objects). As a result, the database does not contain overlapping objects. It was noted for all the applied databases that more feature classes had a negative influence on passability than positive. This results are understandable, as terrain objects in most cases constitute an obstacle for troop movement.

The generated passability maps enable to distinguish consistent areas characterised both by a high and low index of passability easily. Maps generated with use of smaller primary fields (of a side length of 100, 200 and $500 \mathrm{~m}$ ) allow for the presentation of a higher number of smaller terrain obstacles. This makes it possible to visualise on the map more detailed manoeuvring corridors for troops, which should (as long as possible) avoid areas with lower index of passability. It should be noted, that passability maps generated with use of squares of the side length of 100 and $200 \mathrm{~m}$ visualise the course of roads - the key element for passability (Fig. 12). For larger primary fields (1,000 $\mathrm{m}$ and larger), the degree of generalisation increases, so that only larger, consistent impassable areas are visible. These conclusions are important in the context of defining the area of application of the generated maps. Maps developed with the use of the primary fields measuring 100,200 and $500 \mathrm{~m}$, were made on the basis of high resolution spatial databases. As a result, they allow for a detailed presentation of small elements affecting to the passability conditions. This information is a key element used in planning military operations at lower, so-called tactical command levels (platoon, company,

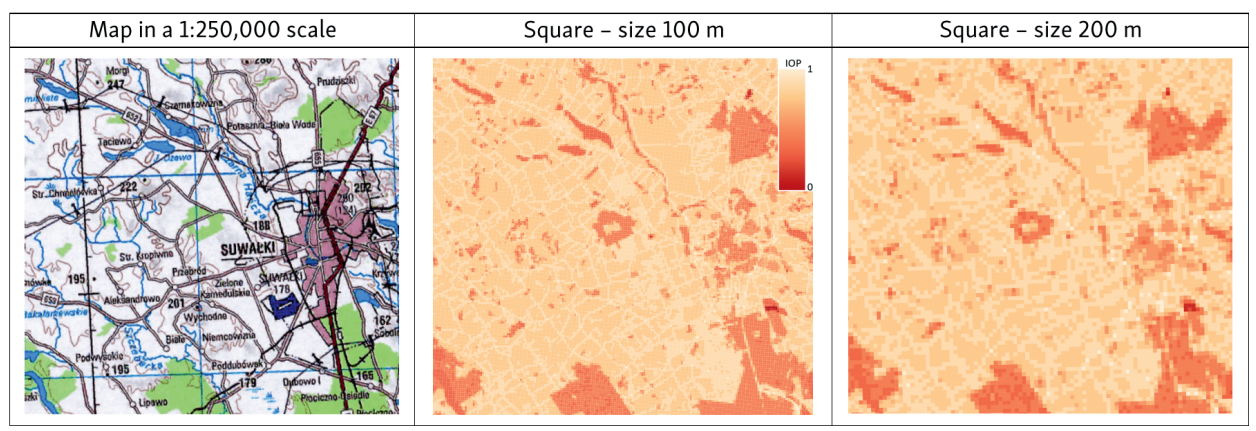

Fig. 12 - Fragment of a passability map generated for primary fields of a side length of 100 and $200 \mathrm{~m}$ and its comparison with the content of a topographic map 
battalion). The use of larger sizes of cells and less accurate spatial database enables the presentation of general (strongly generalized) passability conditions, which is desirable at higher, operational planning levels (brigade, division).

The visual analysis of the generated maps demonstrates that, within the same size of primary field, the distribution of impassable areas is very similar in the all obtained maps. This correlation is also confirmed by very high Pearson Correlation Coefficients (PCC) outcomes between generated maps, which range from 0.7 to 0.9 (Tables 2-7). However, despite the high values of PCC's, maps presenting the spatial distribution of IOP value differences (Tables 8-13) show, that despite selecting the same resistance coefficients $\left(I_{V R F}\right)$, when comparing some maps, there is a large percentage of primary fields differing from each other in a way considerable. This is the case when comparing maps generated using OSM data with maps developed with both VML2 and BDOT. In this case, despite high PCC's, more than $50 \%$ of the IOP's differ from 0.2 to 0.4 from each other. This is because OSM database is organized differently. On the other hand, there is a noticeable similarity between the maps generated from VML2 and BDOT (over $90 \%$ of IOPs do not differ by more than 20\%). For the low-detailed databases (VML1, Corine and BDOO), the absolute difference of IOP's for $70-95 \%$ of cases does not exceed 0.2. The results of comparing maps generated automatically with manually created maps show very large discrepancies between them (especially for squares with a side of over $1,000 \mathrm{~m}$ ). The reason for this is a completely different method of their development (manual selection of NO GO and SLOW GO terrain) and, as well as the use (in accordance with the provisions of normative documents) in the manually created maps, 3 basic classes of passability. It is also worth to pay attention to the fact, that along with the increasing primary field size, the correlation between automatically generated passability maps and the manually created map decreases. This correlation is presented in Figure 13. It shows a linear decrease in the correlation coefficient with the increasing primary field size. Such correlation was noted for all the tested topographic databases.

The visual comparison of generated passability maps, especially those created with use of smaller size primary fields, reveals slight differences in passability for maps based on OSM. This phenomenon manifests itself in a decreased possibility to distinguish impassable areas (the map is more difficult to use, see Table 2 - OSM column). A reverse phenomenon is noticeable for maps generated with use of Corine Land Cover data. In this data, as the number of separated object classes is low (the objects do not overlap), passability classes are clearly distinguishable, which facilitates using the map. It is not obscured by small overlapping elements of different $I_{\mathrm{VRF}}$ coefficients. The measure of scattering of the indices of passability is the standard deviation. It is the lowest for OSM data, for all sizes of primary fields (Fig. 14). A considerably higher value of this estimator was noted for data generated with use of Corine. Figure 15 demonstrates, that the average index of 


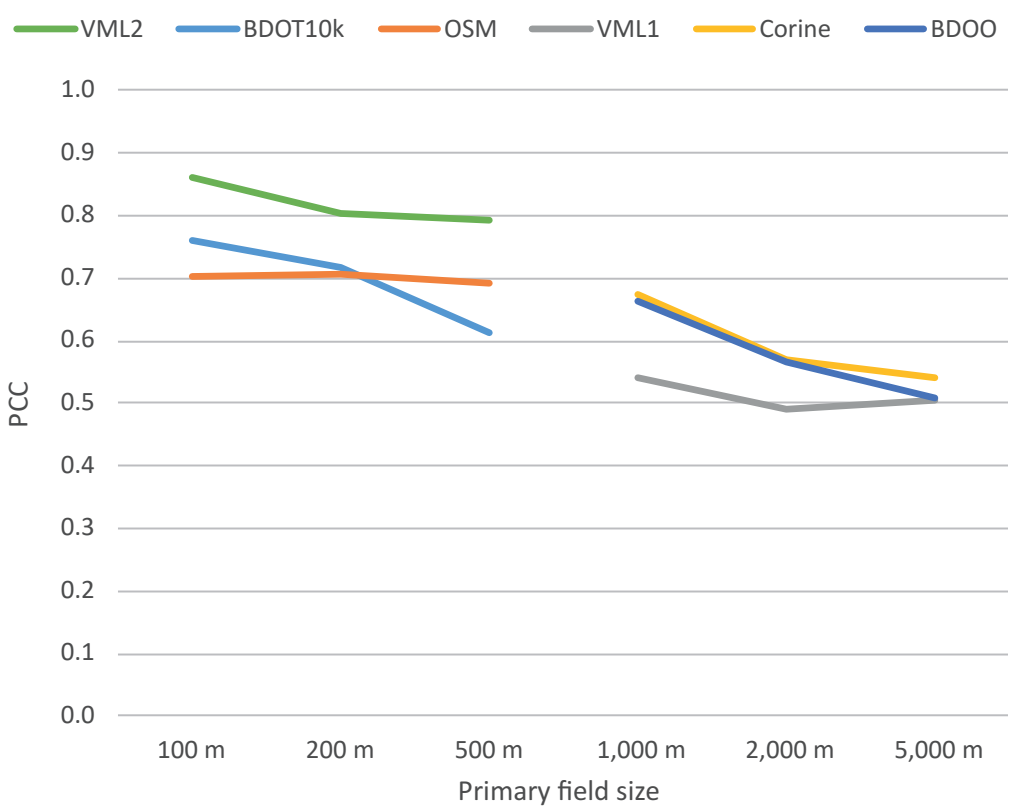

Fig. 13 - Pearson correlation coefficient in reference to manually created map, depending on the primary field size
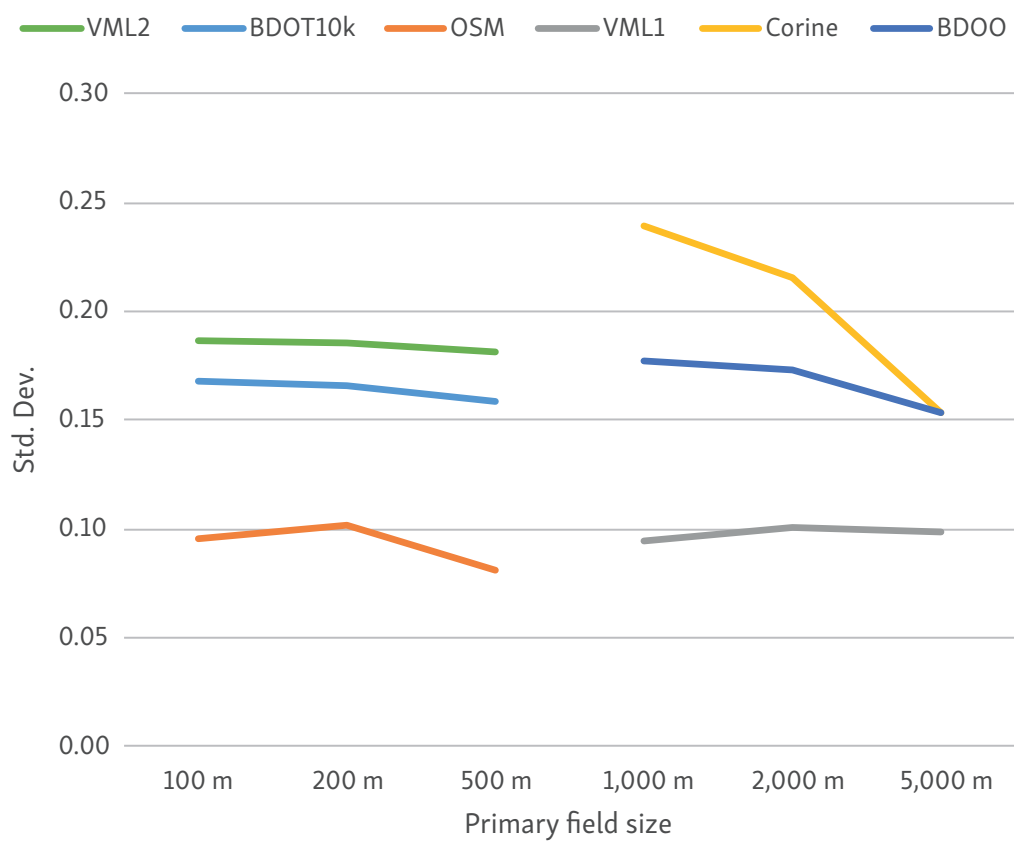

Fig. 14 - The correlation between standard deviation and primary field size 


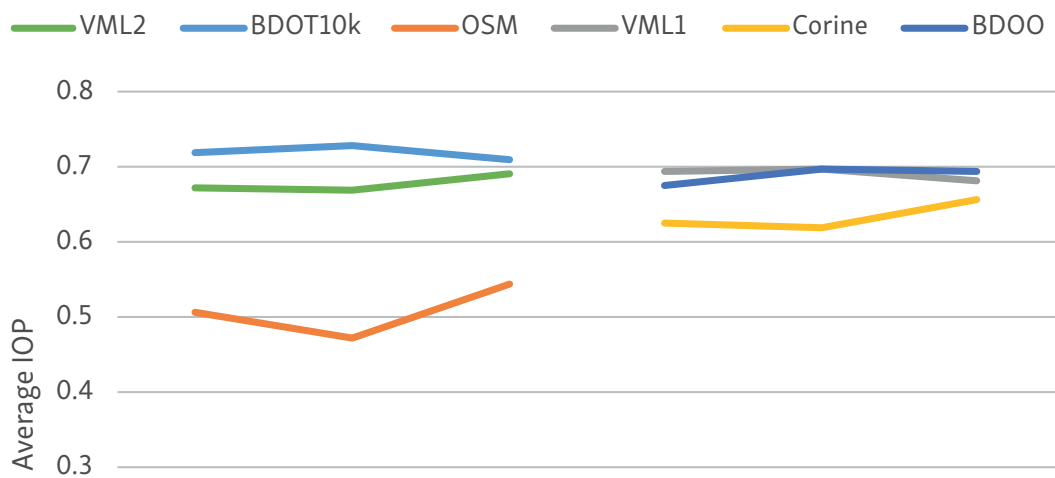

0.2

0.1

0.0

$100 \mathrm{~m} \quad 200 \mathrm{~m} \quad \begin{aligned} & 500 \mathrm{~m} \quad 1,000 \mathrm{~m} \\ & \text { Primary field size }\end{aligned}$

Fig. 15 - The correlation between average IOP and primary field size

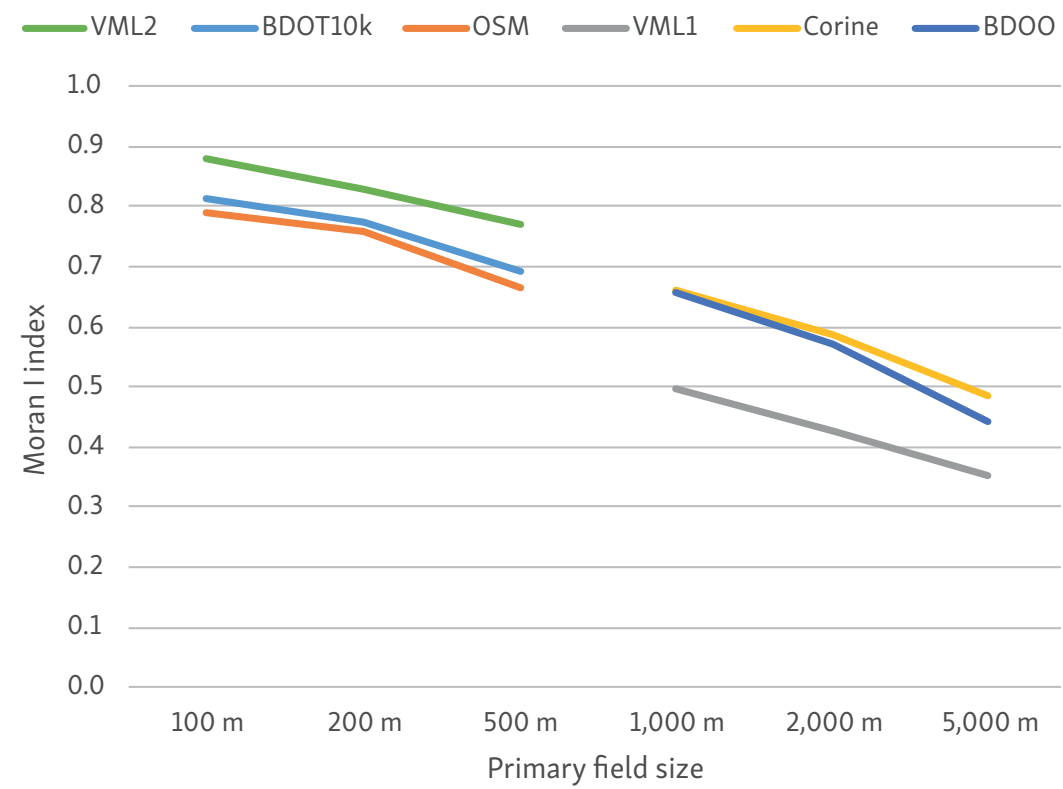

Fig. 16 - The correlation between Moran I index and primary field size 
passability is much lower for OSM data than for the other databases used. This is what causes a noticeable "shift" in the distribution of indices of passability towards lower values. In practice, this results in the fact, that these maps are "darker" than the other ones with the applied method of cartographic visualisation (see Table 2 and compare OSM with other maps).

Generated for small primary fields $(100,200$ and $500 \mathrm{~m})$ histograms, clearly show an increased number of primary fields for IOP's of about 0.8 (VML2 and BDOT) and 0.6 (for OSM data). These fields (mostly) illustrate the course of roads that disappear on maps constructed using larger primary fields. For smaller squares (up to $500 \mathrm{~m}$ ), there is also an increase in the number of primary fields with low passability (about 0.3-0.4). These are impassable areas, such as forests and lakes. Histograms show that increasing the size of the primary field clearly "flattens" the distribution of generated IOPs. This is due to the fact, that with the increase in the size of the primary field, a greater number of objects, affecting on passability in a different way, is located inside this field. In practice, this results in a greater generalization of the content of the maps being created. This is confirmed by the designated global Moran I index. Its value for all generated maps is greater than 0 , which confirms that the IOP's form spatial clusters, especially for the smallest, used primary fields. These clusters, with a similar IOP value, are mainly created by large surface objects (forests, buildings, reservoirs). Moran's coefficient decreases as the size of the primary field increases in linear progression (Fig. 16), which confirms the growing disperse of IOP's spatial distribution.

Interesting results were provided by the analysis of changes in the passability rates along the example routes (Figures 8-11). As expected, the most diversified charts are based on maps built from the smallest basic fields. Their high detail allows for taking into account even relatively small terrain elements that affect on passability (roads, single buildings). The maps made on the basis of low detailed spatial databases (VML1, Corine and BDOO), due to the size of the cell used, already do not include these elements. With these maps, mainly obstacles covering large areas (forests, built-up areas) can be distinguished. Table 14 shows the sum of the IOP's along the measurement lines determined for each map. It is a specific coefficient of resistance of the area, along the routes studied. The differences between these totals are greatest for small sizes of primary fields. This indicates the differences in the content of the maps (e.g. on the Fig. 8, swamps only appear on VML2). For larger fields $(1,000 \mathrm{~m}, 2,000 \mathrm{~m}$ and $5,000 \mathrm{~m})$, the total IOP of the route is practically no different. This analysis also shows that the use of very large primary fields results in the generalization of the content, making the differences between passability virtually unnoticeable (Fig. 10 and 11 for $5 \times 5 \mathrm{~km}$ primary fields). 


\section{Conclusions}

An in-depth analysis of the generated passability maps, enabled us to prove that military VML2 data and the BDOT10k civilian database are best suited for generating maps consisting of primary fields of smaller sizes (side length up to 1,000 m). The other databases are characterised by too low levels of detail (the VML1 and BDOO databases are general maps with a detail level of 1:250,000). As far as the OSM data are concerned, the maps created with use of such data are characterised by a systematic "shift" in the distribution of passability towards lower values. As a result, it is more difficult to notice the differences in terrain passability on maps generated with use of OSM. Although this does not disqualify the database as a source for generating passability maps fully, it requires introducing certain changes, e.g. in the configuration of the analysis parameters i.e. IVRF adjustment. Alternatively, it is also possible to improve the distribution of variables artificially, e.g. by screeching the histogram. On the other hand, the Corine Land Cover data collection seems unsurpassed as a source for generating maps based on larger primary fields (side length 1,000 $\mathrm{m}$ and longer). Maps created with use of this database are the most transparent. What prevents the use of these data for generating maps based on smaller primary fields is the fact, that Corine does not include such key elements for passability as transportation routes (e.g. roads, railways) presented in linear form. They are visible and distinct on maps that sue the smallest primary fields. A compromise solution would be adding them to Corine Land Cover from a different set (this will be the subject of further research).

The presented research results enabled finding and motivating answers to preliminary research questions. Considering the solutions presented above, an essential conclusion of this paper is the fact that "non-military" topographic databases are very well suited for generating military passability maps. These maps are mostly as good as those generated with use of typical military databases (VML1, VML2). Sometimes the application of generally available and free of charge "civilian" databases (such as CLC) may even result in creating better and more legible passability maps. This conclusion should be thoroughly considered by the authorities of military geographic services.

In order to enable comparing the obtained passability maps, the author decided to apply (as far as possible) the same parameters to generate them. However, one should note that the assigned terrain resistance coefficients may be changed freely and adjusted to the structure of the database used. The modification of these coefficients will also enable to adapt the generated passability maps to specific types of troops. An example to prove this may be forests, which constitute a major obstacle for motor vehicles (in the presented examples forests were assigned $I_{v r f}=-0.7$ ). However, for special forces, who have the possibility to penetrate through forests more easily, this coefficient should be higher, e.g. - 0.2 . 
Another very important conclusion from the conducted tests is the fact, that maps generated automatically do not differ considerably from maps created manually by humans. The similarity is the highest for small primary fields (side length 100 and $200 \mathrm{~m}$ ) and it exists for maps generated with use of practically all the tested databases. This means that passability maps generated with use of the VRF method may replace traditional, manually created maps, saving many hours of work of a qualified operator. Finally, one cannot neglect the fact that maps generated with use of the presented method offer more possibilities of interpreting the terrain situation, as they present passability with use of the index expressed within the continuous range from 0 to 1 , while on traditional maps passability is determined only with use of 3 classes: GO, SLOW GO and NO GO.

The research also made it possible to present proposals for selecting the size of fields depending on the scale of the resulting map, and thus its destination. The results of the research can be used to develop maps at various levels of military command. It is worth emphasizing, that the use of the automatic method of terrain classification and calculation of the passability rate, creates grounds for automating the entire process of developing such maps. This is the added value of the work carried out, giving the results of the research an important practical aspect.

Further research will be conducted in the direction of developing the maps of passability for the area of different countries, and with different characteristics of land cover. This would make it possible to examine the universality of the proposed solutions, and consequently to develop procedures, that can be applied in the areas of all NATO countries. In these studies, will be used global spatial database such as MGCP (Multinational Geospatial Co-Production Program). This is product elaborated by military geographic offices of NATO countries (but not only) as part of international cooperation. Currently, this product covers ca. $25 \%$ area of the entire world.

\section{References}

CORINE Land Cover - Copernicus Land Monitoring Service: https://land.copernicus.eu/paneuropean/corine-land-cover/view (13.9.2018).

DIGEST (1998): STANAG 7074, ed. 2: Digital Geographic Information Exchange Standard. Headquarters, Department of US Army, Washington.

ELAK, L., ŚLIWA, Z. (2016): The Suwalki gap - NATO's fragile hot spot. Zeszyty Naukowe AON, $2,103$.

FARR, T.G., ROSEN, P.A., CARO, E., CRIPPEN, R., DUREN, R., HENSLEY, S., KOBRICK, M., PALLER, M., RODRIGUEZ, E., ROTH, L., SEAL, D., SHAFFER, S., SHIMADA, J., UMLAND, J., WERNER, M., OSKIN, M., BURBANK, D., ALSDORF, D. (2007): The Shuttle Radar Topography Mission. Reviews of Geophysics, 2, 45.

Field manual 5-33 Terrain Analysis (1990): Headquarters, Department of US Army. 
GONZALEZ, R., JAYAKUMAR, P., IAGNEMMA, K. (2016): An efficient method for increasing the accuracy of mobility maps for ground vehicles. Journal of Terramechanics, 68, 23-35.

GOODCHILD, M.F. (1986): Spatial autocorrelation. Geo Abstracts Univ. of East Anglia, Norwich.

HOFMANN, A., HOŠKOVÁ-MAYEROVÁ, Š., TALHOFER, V., KOVAŘÍK, V. (2014): Creation of models for calculation of coefficients of terrain passability. Quality \& Quantity, 4, 49, 1679-1691.

HUBÁČEK, M., CEPLOVÁ, L., BRENOVÁ, M., MIKITA, T., ZERZAN, P. (2015): Analysis of vehicle movement possibilities in terrain covered by vegetation. IEEE, 1-5.

JAYAKUMAR, P., MECHERGUI, D., WASFY, T.M. (2017): Understanding the Effects of Soil Characteristics on Mobility.

JAYAKUMAR, P., BRADBURY, M., DASCH, J., GONZALEZ, R., HODGES, H., JAIN, A., IAGNEMMA, K., LETHERWOOD, M., MCCULLOUGH, M., PRIDDY, J., WOJTYSIAK, B. (2018): Next-Generation NATO Reference Mobility Model (NRMM) Development. Technical Report RDP STO-AVT-ET-148.

LESSEM, A., MASON, G., AHLVIN, R. (1996): Stochastic vehicle mobility forecasts using the nato reference mobility model. Journal of Terramechanics, 6, 33, 273-280.

MACLAURIN, B. (2007): Comparing the NRMM (VCI), MMP and VLCI traction models. Journal of Terramechanics, 1, 44, 43-51.

NATO (2003): Stanag 7163, vector map (VMAP) level 1. North Atlantic Treaty Organization.

NATO (2006): MC 296/1 NATO Geospatial Policy, NATO.

MCCULLOUGH, M., JAYAKUMAR, P., DASCH, J., GORSICH, D. (2017): The Next Generation NATO Reference mobility model development. Journal of Terramechanics, 73, 49-60.

NO-06-A015:2012, Terrain - Rules of classification - Terrain analysis on operational level (2012): Polish Ministry of National Defence.

OpenStreetMap Wik: https://wiki.openstreetmap.org/wiki/Main_Page (17. 7. 2018).

POKONIECZNY, K. (2017a): Automatic military passability map generation system. In: 2017 International Conference on Military Technologies (ICMT). 285-292.

POKONIECZNY, K. (2017b): Methods of Using Self-organising Maps for Terrain Classification, Using an Example of Developing a Military Passability Map. In: Dynamics in GIscience. Springer, Cham, 359-371.

POKONIECZNY, K., MOŚCICKA, A. (2018): The Influence of the Shape and Size of the Cell on Developing Military Passability Maps. ISPRS International Journal of Geo-Information, 7, 7.

POKONIECZNY, K., WYSZYŃSKI, M. (2016): Automation of the terrain assessment classification due to passability for the needs of crisis managment. In: https://sgemworld.at/sgemlib/ spip.php?article8445 (13.9.2018).

RYBANSKÝ, M. (2007): Effect of the Geographic Factors on the Cross Country Movement During Military Operations and the Natural Disasters. In: Rerucha, V. (ed.). Univ Defence, Brno, Brno.

RYBANSKÝ, M. (2015): Soil trafficability analysis. In: International Conference on Military Technologies (ICMT) 2015. 1-5.

RYBANSKY, M., HOFMANN, A., HUBACEK, M., KOVARIK, V., TALHOFER, V. (2015): Modelling of cross-country transport in raster format. Environmental Earth Sciences, 10, 74, 7049-7058.

SHOOP, S., KNUTH, M., WIEDER, W. (2013): Measuring vehicle impacts on snow roads. Journal of Terramechanics, 1, 50, 63-71.

TALHOFER, V., HOŠKOVÁ-MAYEROVÁ, Š., HOFMANN, A. (2012): Improvement of digital geographic data quality. International Journal of Production Research, 17, 50, 4846-4859.

VMAP (1993): Military specification MIL-V-89032 Vector Smart Map, Level 2, National Imagery and Spatial Agency. 


\section{ACKNOWLEDGMENTS}

This research was performed on the basis of Vector Map Level 2 and 1 obtained from Polish Military Directorate. The SRTM digital terrain models were obtained in 2017 from NASA's resources (http://www2.jpl.nasa.gov/srtm). The OpenStreetMap database has been downloaded from official OSM repository (http://openstreetmap.org).

This work was supported by the Faculty of Civil Engineering and Geodesy, Institute of Geodesy of the Military University of Technology with the frame of statutory research (grant number PBS 933/2017). 